\title{
Ecological functioning of mudflats: global analysis reveals both regional differences and widespread conservation of functioning
}

\author{
Navodha G. Dissanayake ${ }^{1,2}$, Christopher L. J. Frid ${ }^{2}$, Tarn P. Drylie ${ }^{3}$, \\ Bryony A. Caswell ${ }^{1,4, *}$ \\ ${ }^{1}$ Environmental Futures Research Institute, Griffith University, Gold Coast, Parklands Drive, QLD 4222, Australia \\ ${ }^{2}$ School of Environment and Sciences, Griffith University, Gold Coast, Parklands Drive, QLD 4222, Australia \\ ${ }^{3}$ School of Environmental Science, University of Waikato, Knighton Road, Hamilton 3240, New Zealand \\ ${ }^{4}$ School of Environmental Science, University of Hull, Hull HU6 7RX, UK
}

ABSTRACT: Mudflats - unvegetated, soft-sediment, intertidal habitats - support macrofaunal assemblages that contribute to a number of important ecosystem functions (e.g. food for fish and birds, nutrient and C-cycling). These habitats are widespread but are threatened by increasing pressure from anthropogenic activities. Greater knowledge of the consequences of biodiversity loss for the functioning of ecosystems can aid management, by identifying potential threats. Systematic searches of the Web of Science and SCOPUS identified 163 published datasets of essentially 'pristine' mudflat macrofaunal assemblages, comprising data on 448 taxa from 4 climatic zones and 10 biogeographic regions. Broad-scale patterns of trait distribution confirmed established patterns showing that taxa at low latitudes have smaller body sizes, shorter life spans and more taxa have exoskeletons, and that direct developmental modes are more prevalent at high latitudes. Greater occurrences of burrow dwellers in the temperate zone may support greater rates of sediment turnover, organic matter decomposition and nutrient cycling, whereas in the tropics, tube dwellers provide more biogenic habitat. Despite these trait differences, the overall similarity in trait composition relative to taxonomic composition indicated that globally, mudflats are functionally similar. The functional redundancy observed across regional and climatic boundaries suggests that ecosystem functioning and service delivery will show some resilience in the face of perturbation. However, the growing anthropogenic pressures on coastal mudflats means the risk of system collapse, beyond resilience thresholds, is high. This study illustrates how an extensive body of published literature can provide a foundation for developing a global understanding of ecological functioning in mudflats to inform management responses.

\footnotetext{
*Corresponding author: b.caswell@griffith.edu.au
}

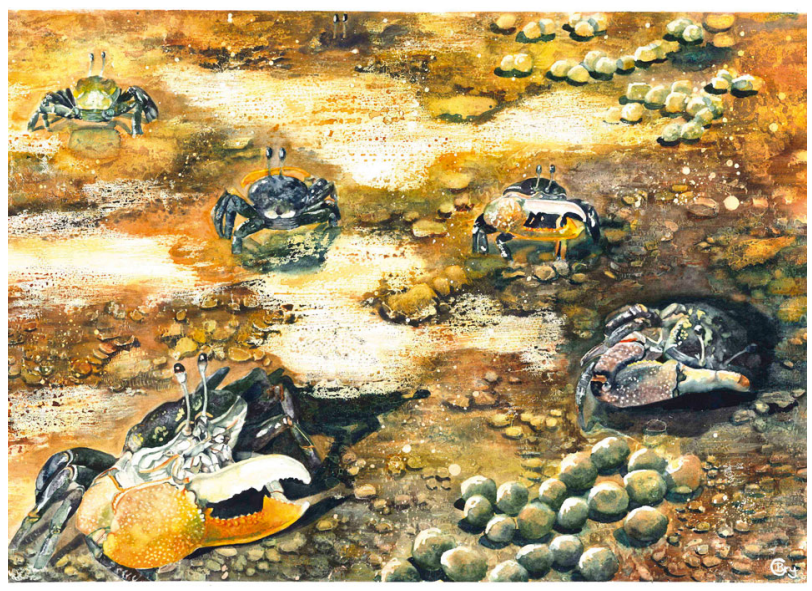

The prevalence of crustaceans, such as fiddler crabs, in tropical mudflats can provide functional equivalence to the burrowing worms of temperate regions.

Illustration: Original artwork by Bryony Caswell

KEY WORDS: Functional redundancy · Biodiversity · Biogeographic trends · Biological traits - Latitudinal variations $\cdot$ Resilience $\cdot$ Environmental management

\section{INTRODUCTION}

Mudflats are ecologically and socio-economically important ecosystems that deliver benefits to human populations worldwide (Costanza et al. 2014). These soft-sediment intertidal habitats, with $>10 \%$ silt and clay (Dyer 1979), support global fisheries through the provision of food and habitat (including important nursery habitats), support resident and migratory

(C) The authors 2018. Open Access under Creative Commons by Attribution Licence. Use, distribution and reproduction are unrestricted. Authors and original publication must be credited. 
populations of birds, provide coastal defences and have aesthetic value. The global value of ecosystem services provided by intertidal systems such as estuaries, including mudflats (total area $\sim 1.8 \times 10^{6} \mathrm{~km}^{2}$ ), is estimated to be US $\$ 5.2 \times 10^{12} 2007 \$ \mathrm{yr}^{-1}$, and a further US $\$ 24.8 \times 10^{12} 2007 \$ \mathrm{yr}^{-1}$ are provided by tidal marshes and mangroves (Costanza et al. 2014). However, intertidal ecosystems are deteriorating globally (Murray 2018) due to increasing anthropogenic pressures (e.g. MEA 2005, Pereira et al. 2010, United Nations 2016). Major localised threats for mudflats include coastal urbanisation, dredging, land reclamation and diffuse and point source pollution (e.g. Frid \& Caswell 2017), which occur against a backdrop of global climate change (IPCC 2013, van der Wegen et al. 2017).

Studies of intertidal community dynamics have deepened our understanding of the ecology of natural systems, providing lessons and/or models that are applicable across systems; such as fundamental insights into e.g. the roles of competition (Dayton 1971), predation (Paine 1966), grazing (Lubchenco \& Gaines 1981) and disturbance in structuring communities (Sousa 1984). These works demonstrate that resident macrofauna are the most important ecosystem components contributing to major ecological processes, often referred to as 'ecosystem functions' (e.g. nutrient cycling, C-cycling, habitat creation and water treatment). These functions underpin the delivery of ecosystem services and benefits (Snelgrove 1997, Hooper et al. 2005, Costello et al. 2015). Consideration of ecosystem functioning within environmental management frameworks was therefore implemented by the United Nations International Convention on Biological Diversity (United Nations 1992), and the protection of ecosystem functioning has become embedded within marine environmental policy (Frid et al. 2008). The United Nations Millennium Ecosystem Assessment (MEA 2005, IPBES 2016) subsequently demonstrated the links between ecosystem functioning and the economic value of ecosystem services. Thus, understanding the scale and nature of changes in biodiversity, ecosystem functioning and the delivery of the associated services has become a research priority.

Individual species' contributions to ecosystem functioning may be determined from the species morphological, physiological, structural or behavioural characteristics, also known as their 'biological traits' (e. g. Mermillod-Blondin 2011, Cardinale et al. 2012). For example, mudflats are rich in organic matter, and its degradation by deposit feeders, and subsequently microbes, is facilitated by bioturbators and underpins water-column primary productivity (Kristensen et al. 2012, Bolam \& Eggleton 2014, Douglas et al. 2017). This is, therefore, a vital process for carbon and nutrient cycling between benthic and pelagic systems (Fitch \& Crowe 2011). Categorising the taxa present according to their biological traits, in addition to their taxonomic identity, allows the functioning of communities and/or ecosystems to be determined (e.g. van der Linden et al. 2012, Caswell et al. in press). Furthermore, an inventory of the functional roles of species gives information on the vulnerability of particular functions and ecosystem services, to biodiversity loss. The functional redundancy theory expects multiple taxa to deliver the same function and so the removal of one or more of these 'redundant species' will not affect overall ecosystem functioning (Naeem et al. 2002, Törnroos et al. 2015). For example, Duffy et al. (2001), in experiments with 3 species of crustacean grazer, showed that the extent of epiphyte growth on seagrass remained constant when the density of any one grazer species was reduced; grazing continued at the same rate. Alternatively, if the taxa removed had a unique functional role within the community, ecosystem functioning may be compromised (Fetzer et al. 2015). In the latter case, the loss of such a 'rivet species' (Walker 1992) can create a dysfunctional ecosystem (Frid \& Caswell 2016). Thus, understanding the patterns of both taxonomic and trait composition can be used to predict the consequences of biodiversity loss for the functioning of the system, and so inform management of potential threats.

Macroscale ecological patterns, such as those described by differences in taxonomic composition, can reveal how species respond to environmental change (Gaston 2000, Pereira et al. 2010, Villarino et al. 2018). The Census of Marine Life initiative (Costello et al. 2010, Snelgrove 2010) has recently documented global patterns of marine biodiversity, and global syntheses of the biogeographic distributions of many major macrofaunal groups have also been compiled (e.g. Boschi 2000, Crame 2000, Rex et al. 2005, Blazewicz-Paszkowycz et al. 2012, Poore \& Bruce 2012). These works suggest that broad-scale patterns exist within both marine and terrestrial systems, such as higher biodiversity at low latitudes (Gaston 2000, Hillebrand 2004), although there are several exceptions (e.g. Stuart-Smith et al. 2013, Villarino et al. 2018). For instance, some taxonomic groups reach maximum diversity at the poles (e.g. subtidal sponges; Brandt et al. 2007) or in temperate regions (e.g. seaweeds; Gaston 2000). Similarly, an apparent global cline in biodiversity with latitude has 
been documented in mudflats (Attrill et al. 2001, Dittmann 2002; from 19 to 20 sites each), and differences in taxonomic composition have been documented between intertidal flats in different regions (McLachlan \& Dorvlo 2005-161 sites) Gray \& Elliott 2009 - 12 sites, Defeo et al. 2017 - 263 sites). Whilst global patterns of biodiversity are driven largely by differences in climate, regional differences are attributable to historic patterns of speciation and biogeography (e.g. Schneider \& Schmittner 2006), or anthropogenic activities such as shipping (Gollasch \& Riemann-Zürneck 1996).

Understanding macroscale variations in ecosystem functioning, and how biodiversity loss may impact functioning, is crucial given the recent realignment of management strategies to focus on ecosystem service delivery. In terrestrial systems, it has been demonstrated that changes in the functional composition of communities are responsible for most variations in ecological functioning (Tilman et al. 1997, Hooper et al. 2005). Thus, to ensure the continued provision of ecosystem services, the conservation of biological trait diversity may be more important than preventing the loss of taxonomic diversity (e.g. Frid et al. 2008, Cadotte 2011, Hemingson \& Bellwood 2018). Although marine ecosystems have not been subjected to the same level of scrutiny as terrestrial ecosystems (e.g. Hendriks \& Duarte 2008), investigations of macroscale patterns of functional diversity and/or ecological functioning have been conducted in seagrass and mangrove habitats and for coral reef fish populations (Stuart-Smith et al. 2013, Hemingson \& Bellwood 2018). However, no global scale analyses of ecosystem functioning have been undertaken for soft sediment systems.

Given the ecological and economic importance of intertidal mudflats, it is appropriate to consider whether global and regional differences in taxonomic composition confer differences in trait composition, producing variations in the ecological functioning of these systems. In the present study, a quantitative systematic approach was adopted to compile data on the taxonomic composition of mudflat assemblages world-wide, and we employed biological traits as proxies for predicting global variations in ecosystem functioning. From this we suggest the extent to which ecologically similar species could provide resilience in these systems (e.g. Folke et al. 2004, Douglas et al. 2017).

This study aimed to investigate whether taxonomic and biological trait composition differed between the mudflats of climatic zones and biogeographic regions, and to determine whether these differences would manifest as differences in the ecological functioning of the biogeographically distinct mudflats. To the best of our knowledge this study is the first to combine detailed observations of local species pools and biological traits to explore differences in mudflat functioning at a global scale.

\section{MATERIALS AND METHODS}

\section{Data compilation}

The 2 main databases of peer-reviewed scientific literature, SCOPUS (Elsevier; elsevier.com) and Web of Science (WoS) (Thomson ISI; webofknowledge. com), were searched to acquire data on the taxonomic composition of macroinvertebrate mudflat communities. Two independent searches were performed using different criteria (Table 1, Fig. 1). A preliminary search (Search 1) of WoS only (Table 1) identified all published papers on marine, estuarine

Table 1. Details of the 2 independent searches to identify peer-reviewed literature on mudflat macrofauna. Search 1 aimed to provide the overall context of published material on mudflat macrofauna nested within all studies of macrofauna. For Search 2, different key search term combinations and Boolean operators were used to identify publications from both databases. The combination that produced the greatest number of publications (bold) were considered the initial sample (Fig. 1). ${ }^{*}$ Refers to wildcard search functions. All searches were completed on 31 December 2016

\begin{tabular}{|c|c|c|}
\hline Theme & SCOPUS & WoS \\
\hline Search 1: macrofauna OR macroinvertebrates & - & 14263 \\
\hline Search within 1: intertidal & - & 1018 \\
\hline Search within 2: mud* & - & 283 \\
\hline $\begin{array}{l}\text { Search 2: } \\
\text { (a) mudflat AND macro* AND *fauna OR "intertidal mud" AND macro* AND *fauna } \\
\text { OR "mud flat" AND macro* AND *fauna }\end{array}$ & 187 & 154 \\
\hline (b) "Mudflat" AND macro* OR "mud flat" AND macro* OR "intertidal mud" AND macro* & 441 & 374 \\
\hline (c) ("mudflat" OR "mud flat" OR "intertidal mud") AND macro* & 31 & 656 \\
\hline
\end{tabular}




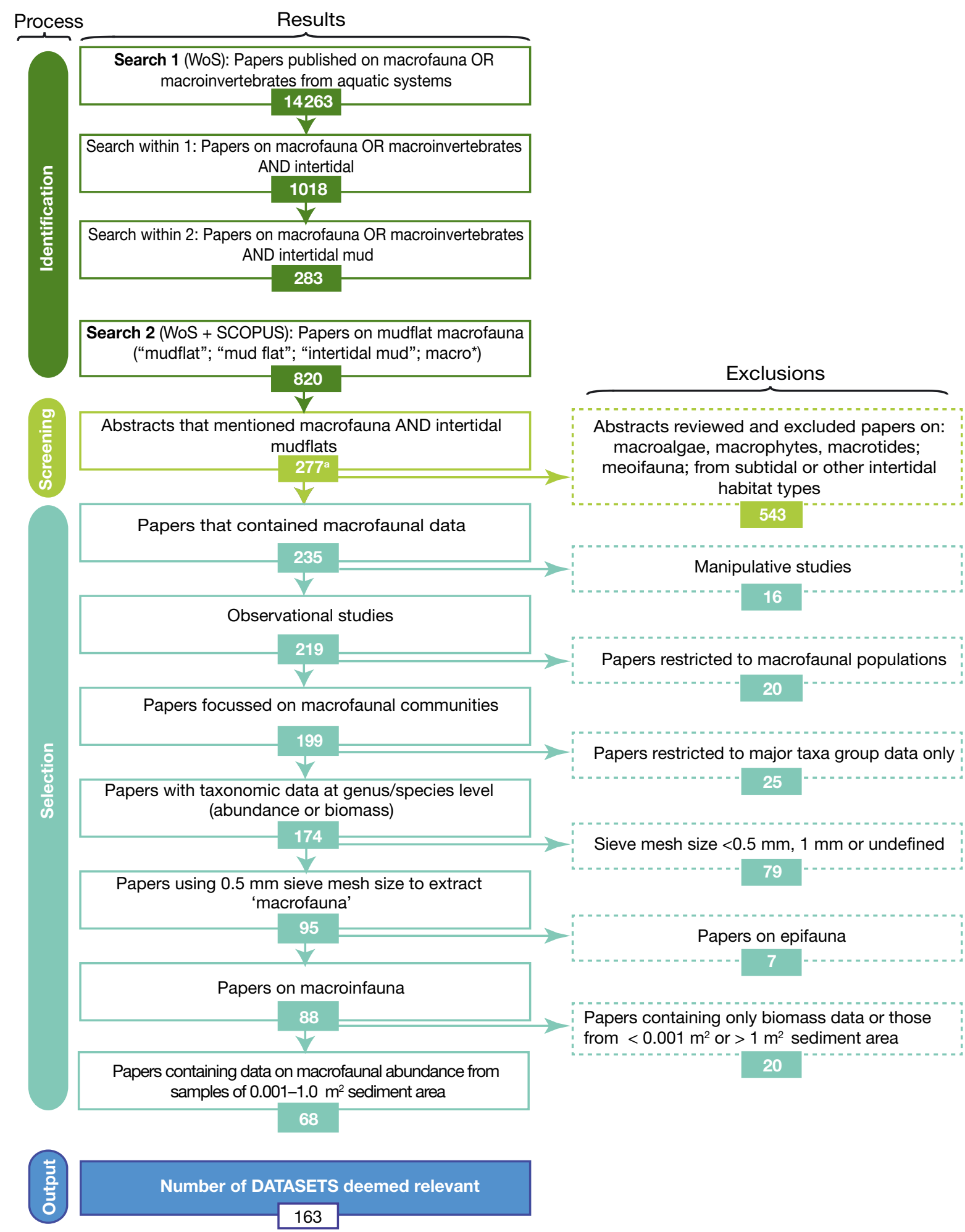

Fig. 1. Flow diagram of process for identifying publications, screening abstracts, and selection of publications from which data could be extracted. Excluded publications are also shown (right-hand column). A total of 68 papers were found to contain data that were collected using comparable methodologies, which equated to 163 unique datasets used for the analysis of taxonomic and biological traits composition in the present study. Note: Mudflats were defined as locations with sediments having $>10 \%$ mud-sized particles $(<0.63 \mu \mathrm{m}$ diameter, based on the Folk classification; studies which did not disclose sediment particle size were classified as 'mud' if so attributed by the authors). ${ }^{\text {a }} 277$ papers with 114 unique to Web of Science (WoS); 50 unique to SCOPUS; 113 indexed in both databases 
and freshwater systems. Two further searches were performed within those results to determine how many were intertidal studies and, of those, how many were mudflat studies.

A review of a subsample $(n=20)$ of papers from the preliminary WoS search results on mudflat macrofauna identified suitable search terms for selecting publications for data extraction (Table 1). Wildcard functions (e.g. macro*) were used to incorporate all possible variants of terms for which there were synonyms (e.g. mudflat, intertidal mud, macrofauna, macroinvertebrate, macrobenthic, macrozoobenthos), and quotation marks were used to search for compound terms. Database searches were completed using the selected key terms connected by Boolean operators in different combinations, and this generated a maximum of 441 publications in SCOPUS (spanning 1977 to 2016) and 656 publications in WoS (spanning 1900 to 2016; Table 1). The search terms were applied to the article title and abstract in both databases, to the 'key words' fields in SCOPUS, and to the 'author keywords' and 'keywords plus' fields of WoS (these differences were imposed by variations in the 2 database search engines).

The list of publications was imported into Endnote ${ }^{\circledR}$ v. X8.2 (endnote.com) and duplicates were removed. This produced 820 unique relevant publications, the abstracts of which were individually screened, and only those that focused on mudflat macrofaunal composition were retained (277 papers; Fig. 1). Metadata were compiled for each paper; comprising the aims and objectives of the study, latitude and longitude of sampling sites, country, habitat type, whether the study was observational or experimental in nature, the type of taxonomic information included (e.g. level of taxonomic classification, taxa abundance or biomass), living habit of study subjects (e.g. infauna or epifauna), sampling procedure (gear type, sampled area, sampling depth, sample volume and sieve mesh size), season and year. Datasets were assigned to 1 of 4 climate zones based on their origin: polar - north and south of $60^{\circ}$ latitude; temperate$40^{\circ}$ to $60^{\circ}$ north and south; subtropical-between $23^{\circ}$ $27^{\prime}$ to $40^{\circ}$ north and south; and tropical $-0^{\circ}$ to $23^{\circ} 27^{\prime}$ north and south. They were also categorised into marine biogeographic regions, according to the classification of Spalding et al. (2007).

Using the metadata, datasets were selected from within the 277 publications that yielded quantitative data (Fig. 1) that could be used to determine global variations in taxonomic composition, biological traits composition and in turn, ecosystem functioning. Selection criteria were applied to maximise the com- parability of the datasets by reducing methodological inconsistencies. The selected datasets were from (1) field-based observational studies that recorded the abundance of macrofaunal taxa (retained on a $0.5 \mathrm{~mm}$ mesh) in mudflats (>10\% silt and clay, sensu Dyer 1979) and (2) from sites characterised by the original authors as 'pristine' or 'relatively undisturbed reference sites'. A total of 88 publications were identified, containing 248 datasets, subsequently further refined by excluding datasets for which comparisons were inappropriate, i.e. that used disparate sampling volumes or effort (Fig. 1), or that recorded a total taxa richness of $<3$. This process produced 163 datasets (68 papers) that contained data on the taxonomic composition of mudflat communities collected using comparable methodologies (Fig. 1).

Fauna retained on a $0.5 \mathrm{~mm}$ mesh sieve is the most frequently used operational definition of 'macrofauna' (Gray \& Elliott 2009), however for reasons of expediency some studies use a $1.0 \mathrm{~mm}$ mesh. The problem of comparing data from studies using different mesh sizes has long been recognised (Reish 1959). Rees (1984), for example, showed that for temperate subtidal benthos, a $1 \mathrm{~mm}$ mesh captures $77 \%$ of the individuals and $69 \%$ of the species retained on a $0.5 \mathrm{~mm}$ mesh. To date, no mechanism exists for consistently estimating the differences between assemblages retained on sieves of differing mesh size because the retention of macrofauana varies between locations. For this reason our analyses were limited to datasets that employed the more commonly used $0.5 \mathrm{~mm}$ mesh.

\section{Biological traits analysis}

Taxonomic data were first checked for errors, inconsistencies and changes in taxa names since publication (using the World Register of Marine Species, WoRMS Editorial Board 2016, www.marinespecies.orgi). Biological traits analysis (BTA) (Bremner et al. 2006) was used to quantify the potential contribution of taxa towards the delivery of selected ecosystem functions (Table 2). Ten morphological, life history and behavioural traits were selected that influenced fundamental mudflat functions mediated by macrofauna (Table 2). For example, organisms with small body sizes and short life spans may facilitate organic C-cycling, whilst taxa that dwell near the sediment surface are most likely to be consumed by predators. Taxa that make a significant contribution to nutrient cycling included those with deepburrowing and deposit-feeding habits (Snelgrove 1997, Costello et al. 2015) (Table 2). 
Table 2. The 10 biological traits and 41 trait modalities used to characterise mudflat macrofaunal taxa and their anticipated contribution to ecosystem functions. Max.: maximum; OM: organic matter

\begin{tabular}{|c|c|c|}
\hline Trait & Modalities & Ecosystem functions \\
\hline \multicolumn{3}{|l|}{ Morphological traits } \\
\hline A. Adult max. body length & (1) $<1 \mathrm{~cm}_{i}(2) 1-3.0 \mathrm{~cm}_{i}(3) 3.1-5 \mathrm{~cm}_{i}(4)>5 \mathrm{~cm}$ & $\begin{array}{l}\text { Nutrient cycling; sediment turnover; OM } \\
\text { decomposition }\end{array}$ \\
\hline B. Body shape ${ }^{a}$ & $\begin{array}{l}\text { (1) Round-oval; (2) rectangular-subrectangular; } \\
\text { (3) vermiform }\end{array}$ & Nutrient cycling; sediment turnover \\
\hline C. Anti-predator adaptations ${ }^{\mathrm{b}}$ & $\begin{array}{l}\text { (1) Unprotected; (2) avoidance; (3) exoskeleton; } \\
\text { (4) body projections; (5) chemical deterrents }\end{array}$ & $\begin{array}{l}\text { Food for predators; C-cycling; biogenic habitat } \\
\text { creation }\end{array}$ \\
\hline \multicolumn{3}{|l|}{ Life history traits } \\
\hline D. Living habit & $\begin{array}{l}\text { (1) Attached; (2) burrow dweller; (3) tube dweller; } \\
\text { (4) free living }\end{array}$ & $\begin{array}{l}\text { Nutrient cycling; sediment turnover; OM } \\
\text { decomposition; biogenic habitat creation }\end{array}$ \\
\hline E. Longevity & $(1)<1 \mathrm{yr} ;(2) 1-2 \mathrm{yr}_{i}(3) 3-5 \mathrm{yr}_{i}(4) 6-10 \mathrm{yr}_{i}(5)>10 \mathrm{yr}$ & $\begin{array}{l}\text { Food for predators; nutrient cycling; OM } \\
\text { decomposition }\end{array}$ \\
\hline F. Larval development & (1) Direct; (2) planktotrophic; (3) lecithotrophic & Food for predators; C-cycling \\
\hline \multicolumn{3}{|l|}{ Behavioural traits } \\
\hline G. Feeding & $\begin{array}{l}\text { (1) Deposit feeder; (2) suspension/filter feeder; } \\
\text { (3) predator/scavenger; (4) grazer }\end{array}$ & Nutrient cycling; C-cycling \\
\hline H. Sediment dwelling depth ${ }^{c}$ & (1) Epifaunal; (2) $0-2 \mathrm{~cm}_{i}$ (3) $2.01-5 \mathrm{~cm}_{i}(4)>5 \mathrm{~cm}$ & $\begin{array}{l}\text { Sediment turnover; nutrient cycling; secondary } \\
\text { production }\end{array}$ \\
\hline I. Mobility & $\begin{array}{l}\text { (1) Free living; (2) limited movement; (3) sedentary; } \\
\text { (4) Semi-pelagic }\end{array}$ & $\begin{array}{l}\text { Sediment turnover; nutrient cycling; } \\
\text { OM decomposition }\end{array}$ \\
\hline J. Bioturbation ${ }^{\mathrm{d}}$ & $\begin{array}{l}\text { (1) None; (2) surface modifier; (3) biodiffusor; } \\
\text { (4) regenerator; (5) upward/downward conveyor }\end{array}$ & $\begin{array}{l}\text { Sediment turnover; nutrient cycling; } \\
\text { OM decomposition }\end{array}$ \\
\hline \multicolumn{3}{|c|}{${ }^{\text {a}}$ Length:width ratio of $\mathrm{B} 1=1-2 ; \mathrm{B} 2=3-10 ; \mathrm{B} 3>10$} \\
\hline \multirow{2}{*}{\multicolumn{3}{|c|}{$\begin{array}{l}{ }^{\mathrm{b}} \mathrm{C} 2=\text { burrows/tubes/immobilisation; } \mathrm{C} 3=\text { exoskeletons including shells/tubes/scales/hard epidermis; C4 = body projections such as } \\
\text { spines; C5 = chemical deterrents including mucous production } \\
\text { 'Sediment dwelling depth A2-A4 applies to infauna only }\end{array}$}} \\
\hline & & \\
\hline \multicolumn{3}{|c|}{$\begin{array}{l}{ }^{\mathrm{d} B i o t u r b a t i o n ~ i n c l u d e s: ~} \mathrm{~J} 1=\text { no bioturbation; } \mathrm{J} 2=\text { surface modifiers that bioturbate the sediments near the surface; } \mathrm{J} 3=\text { biodiffusors that } \\
\text { constantly and randomly mix; } \mathrm{J} 4=\text { upward/downward conveyors that feed head up or down and transport sediment from depth to } \\
\text { surface or vice versa; } \mathrm{J} 5=\text { regenerators that excavate continuously maintaining burrows (Kristensen et al. 2012, Queirós et al. 2013) }\end{array}$} \\
\hline
\end{tabular}

Information on the biological traits of the recorded taxa were sourced from taxa-specific literature or syntheses (e.g. Fauchald \& Jumars 1979, Kristensen et al. 2012, Kicklighter \& Hay 2006, Queirós et al. 2013) and suitable databases, e.g. the Biological Traits Information Catalogue (MarLIN 2006), Marine Species Identification Portal (Bioinformatics 2018), BOLD systems (Ratnasingham \& Hebert 2007) and Polytraits (Faulwetter et al. 2014). Each of the 10 traits were represented by 3 to 5 subcategories, or modalities; e.g. feeding mode was subdivided into deposit feeder, suspension and filter feeder, predator and/or scavenger, and grazer (Table 2). The affinity of each taxon to a trait modality was coded using a 'fuzzy coding' procedure (Chevene et al. 1994). This method allowed each taxon to exhibit multiple modalities reflecting diverse behaviours that occur in nature. The score assigned to each modality (e.g. $0=$ species had no affinity to that modality, $1.0=$ complete affinity) was such that the scores for a trait summed to 1 . When the affinity of a taxon for a modality was unknown, higher taxon level information (e.g. genus < order < class) were used. Taxon abundances were multiplied by the trait modality scores to produce a trait-abundance by site matrix.

\section{Data analyses}

Univariate analyses were performed using SPSS Statistics 22 (IBM) and multivariate analyses in PRIMER 6 Beta (Plymouth Routines in Multivariate Ecology Research Ltd.). The metadata from the 227 WoS datasets were used to identify trends in research effort on mudflat macrofauna through time, the number of papers published in each year were standardised to the total number of papers published in the WoS 'marine and freshwater biology' subject category each year. Also, variations in the scientific focus through time, based on the aims and objectives of each study, were explored for all papers $(n=277)$. Pearson's correlation was used to identify the trends 
in both research effort and scientific focus through time.

The total number of papers recorded in each climatic zone and biogeographic region were standardised to the actual sea surface area $\left(\mathrm{km}^{2}\right)$ (Arc Map 10.3) in each zone and region and were compared using Chi-squared tests. Taxonomic and trait richness in each climatic zone were estimated using Ugland, Gray and Ellingsen (UGE) (Ugland et al. 2003) and Michaelis-Menton taxa accumulation curves.

The taxa abundance by site data were $\log (x+1)$ transformed prior to analysis to reduce the impact of dominant and rare taxa. The Bray-Curtis similarity of taxonomic and trait composition was compared between climatic zones and biogeographic regions using ordination (non-metric multidimensional scaling; nMDS). Analysis of similarity (ANOSIM) provided a pairwise comparison of the regions and zones, and similarity percentage routines (SIMPER) helped identify taxa and traits that contributed to these differences. The mean traits (natural logarithm transformed) and proportion of taxa (arcsine transformed) that contributed substantially to dissimilarity between zones and regions were compared using 1-way ANOVA or Mann-Whitney $U$-tests (Table 4). Pair-wise correlations between the 41 trait modalities ( $n=448$ taxa) showed that 3 pairs were correlated (Pearson's correlation, $\mathrm{p}<0.001, \mathrm{R}^{2}>0.25$ ) and the highest association $\left(\mathrm{R}^{2}=0.49\right)$ was between the 'free living' habit (D4) and the 'epifauna' trait (H1, Table 1). It seems unlikely that this small degree of correlation between traits will have inflated the Bray-Curtis similarity between datasets.

\section{RESULTS}

\section{Extent of published work on mudflat macrofauna}

Within the Web of Science (WoS) there were 14263 peer-reviewed papers on "macrofauna OR macroinvertebrates" from aquatic systems, of which 1018 considered those inhabiting intertidal ecosystems (Fig. 1), and of those, 283 were from mudflats. The second search identified 656 peer-reviewed publications on mudflat macrofauna in WoS, whereas an equivalent search in SCOPUS yielded 441 (Table 1, total no. of papers 1097). After duplicates were removed the total number of papers was 820 (Fig. 1). After reviewing the abstracts of the 820 unique papers, 277 publications were found to directly focus on macrofaunal assemblages (Fig. 1). The proportion of papers on mudflat macrofauna to those published on marine and freshwater biology did not change through time (Fig. 2A; Pearson Correlation $r$ [40] = $0.174, p>0.05$ ) and represented $0.03 \%$ of those published in "marine and freshwater biology" each year between 1975 and early 2017.

The objectives of the 277 papers described 4 broad research categories comprising studies of (1) biodiversity, (2) environmental factors, (3) human impacts, and (4) ecosystem processes and functioning. Over the entire period the greatest focus was on the influence of environmental factors on benthic macrofauna (34\% of papers), followed by taxonomic composition $(29 \%)$, and the impacts of human activities (19\%). The remainder $(18 \%)$ investigated ecological functioning or processes. Few studies $(<5 \%)$ spanned $>1$ research area, and there were no significant changes in focus throughout the $40 \mathrm{yr}$ (Pearson correlation $\mathrm{p}>$ 0.05).

The mudflat macrofaunal studies were derived from 4 climatic zones and 10 of the 12 biogeographic regions classified by Spalding et al. (2007). The proportion of papers published (standardised by the sea
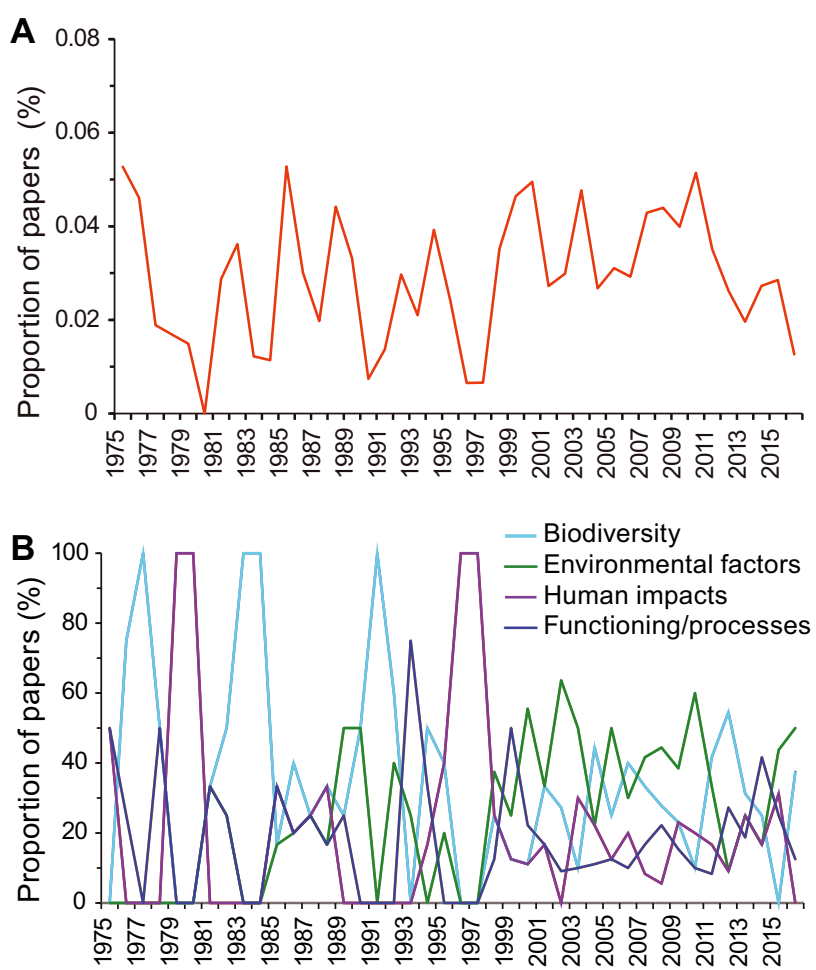

Fig. 2. Global trends in the number of peer-reviewed publications on mudflat macrofauna between 1975 and 2016. (A) Those identified from Web of Science (WoS) $(n=227)$ as a proportion of papers in the discipline "marine and freshwater biology" ( $\mathrm{n}=725277$ ) in each year. (B) Papers within each of 4 research categories (from WoS and SCOPUS; $\mathrm{n}=$ 277 ) as a proportion of the total number of mudflat papers published in each year 
surface area of each zone and region) significantly differed between zones (Chi-squared test, $\chi^{2}[3, \mathrm{n}=$ $277]=91.99, \mathrm{p}<0.001)$ and regions (Chi-squared test, $\left.\chi^{2}[9, \mathrm{n}=277]=94.83, \mathrm{p}<0.001\right)$. Half of the papers contained data from mudflats in the temperate climatic zone, $32 \%$ were from the subtropics, $14 \%$ from the tropics and only $2 \%$ were from the polar zone. Additionally, $50 \%$ of publications were generated from the Temperate $\mathrm{N}$ Atlantic while the Central Indo-Pacific, Temperate Australasia and Temperate N Pacific each accounted for a further 7 to $14 \%$, and $<4 \%$ came from each of the 7 remaining regions.

A total of 68 publications contained data on taxonomic composition, collected using relatively consistent methodologies that were suitable for metaanalyses (Fig. 1). These studies contained 163 unique datasets that included information on 448 taxa from
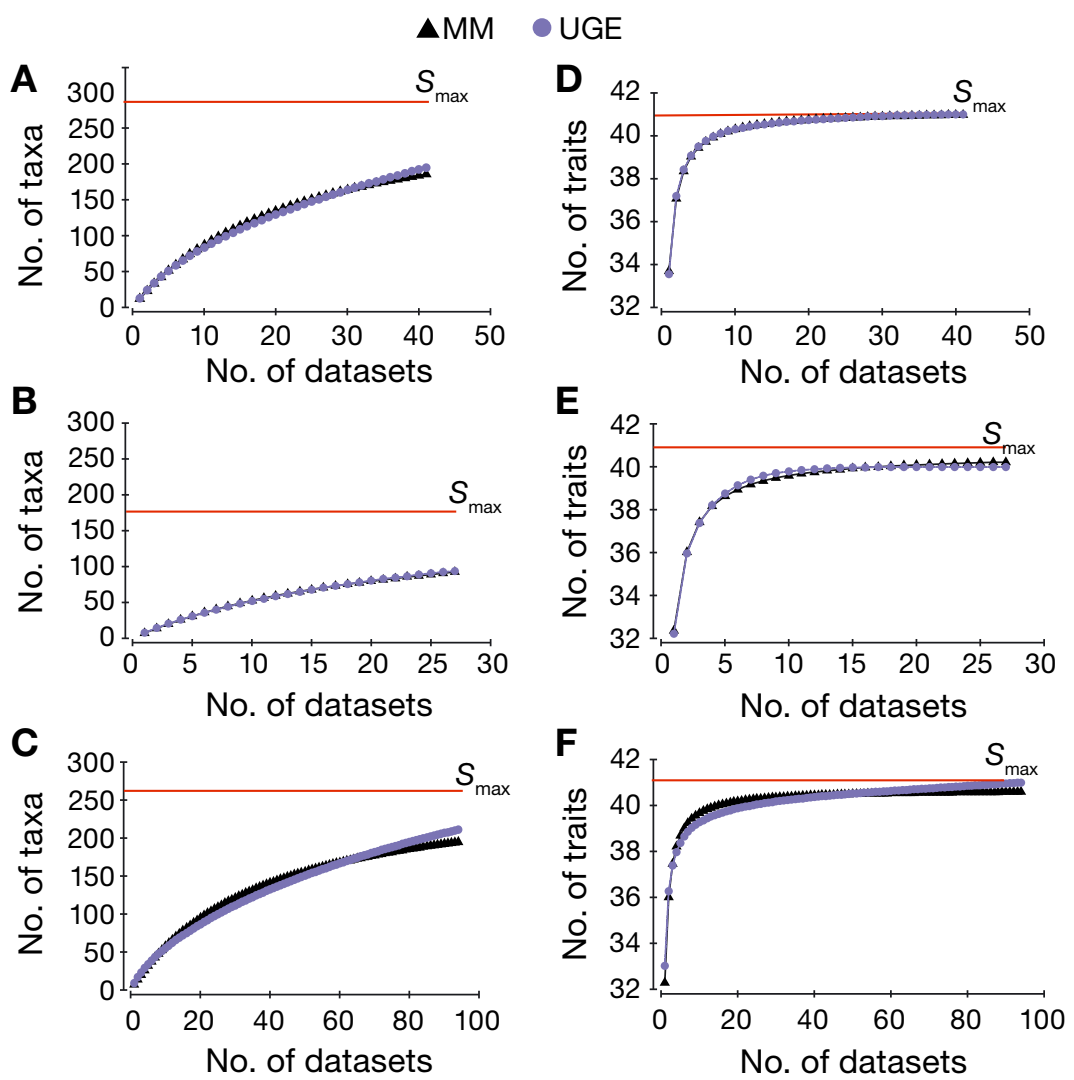

Fig. 3. Taxa accumulation plots for (A) tropical (observed taxa, $S_{\text {obs }}=195$; maximum taxa, $S_{\max }=292$, from 41 datasets); (B) subtropical $\left(S_{\mathrm{obs}}=94, S_{\max }=167\right.$ taxa, from 27 datasets); (C) temperate climatic zones $\left(S_{\text {obs }}=211, S_{\max }=272\right.$ taxa, from 94 datasets). Biological traits accumulation plots for (D) tropical $\left(S_{\text {obs }}=41\right.$, $\left.S_{\max }=41.2\right) ;\left(\right.$ E) subtropical $\left(S_{\text {obs }}=41, S_{\max }=40.6\right) ;($ F) temperate climatic zones $\left(S_{\mathrm{obs}}=41, S_{\max }=40.7\right)$. Estimates are based on Michaelis-Menton (MM) and Ugland, Gray and Ellingsen (UGE) projections. Estimates were generated from 999 resamples of the observed $\left(S_{\text {obs }}\right)$ taxa and traits across 163 datasets. Red lines indicate the projected maximum taxa and trait richness $\left(S_{\max }\right)$ generated using the Michaelis Menton equation across 4 climatic zones and 10 of the biogeographic regions. Of the total number of taxa recorded in each climatic zone, $\sim 75 \%$ were classified to species and $\sim 18 \%$ to genus in both the subtropical (94 taxa) and temperate (211 taxa) zones. In the tropics $~ 60 \%$ (195 taxa) were described to species and $\sim 30 \%$ to genus level.

\section{Taxa and biological trait richness}

Differences between the number of datasets, and hence sampling effort, for each climatic zone meant that the observed taxa richness ( $\left.S_{\text {obs }}\right)$ may not reflect actual biogeographic patterns, and so projections of the maximum number of taxa $\left(S_{\max }\right)$ in each zone were produced. The UGE and Michaelis-Menton projections showed that the taxa pool was greatest in the tropics, followed by the temperate zone, and the least taxonomically rich benthos occurred in the subtropics (Fig. 3A-C). The projected trait richness was similar between the tropics, subtropics and temperate zones (Fig. 3D-F).

\section{Regional differences in the taxonomic and trait composition of mudflat macrofauna}

The Arctic, Western Indo-Pacific and Temperate South African regions were each represented by only one dataset (see Fig. 5B) and so were excluded from the analyses. The taxonomic (ANOSIM R $=0.66, \mathrm{p}<0.01$; Fig. $4 \mathrm{C}$ ) and trait (ANOSIM, R = 0.11, $\mathrm{p}<0.01$; Fig. 4D) composition differed significantly between the remaining 7 biogeographic regions. Pairwise ANOSIM showed that 17 pairs of regions significantly differed taxonomically (Table 3 ), while biological trait composition differed between the Central Indo-Pacific and Tropical Atlantic regions only $(\mathrm{p}<$ 0.01 ).

The taxonomic composition of mudflats in the Temperate N Atlantic, Central Indo-Pacific and Tropical Atlantic regions significantly differed from all other regions (Fig. 4C, Table 3). Similarly, the Temperate S American region differed from all regions except 


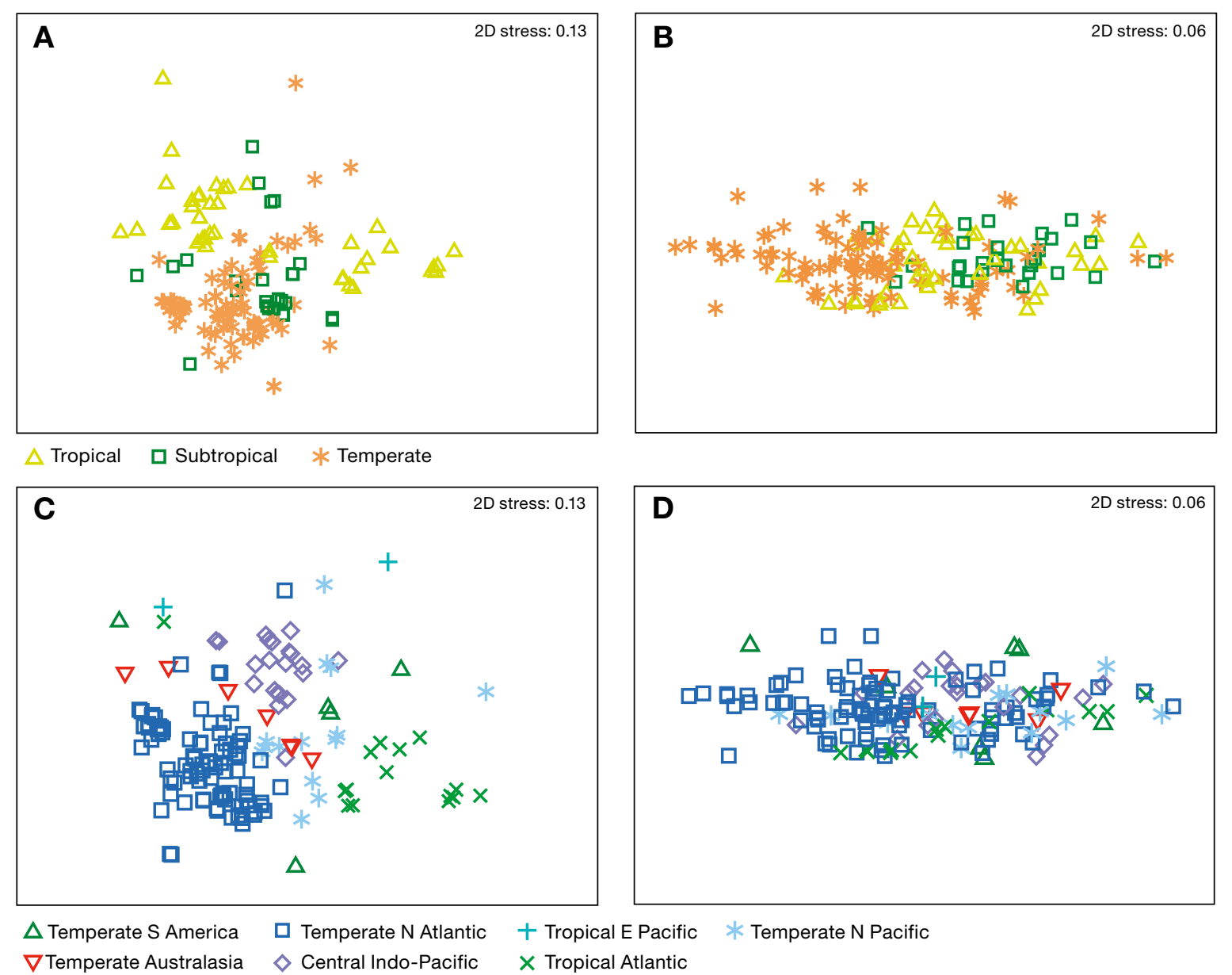

Fig. 4. nMDS ordination plot of the Bray-Curtis similarity of global mudflat macrofaunal assemblages. (A) Taxonomic composition and (B) trait composition between the 3 climatic zones. (C) Taxonomic composition of mudflats in the 7 biogeographic regions (the Western Indo-Pacific, the Arctic and Temperate S Africa were excluded because they contained only 1 dataset);

(D) trait composition of mudflats in the 7 biogeographic regions

for the Tropical E Pacific (Table 3). Delineation of the Temperate S American region was less geographically constrained than most other regions (Fig. 5B) because it spans both the Pacific and Atlantic coasts, thus the taxonomic composition is heterogeneous. Of the 448 taxa found across all mudflat assemblages, 43 species, 6 genera and 1 family occurred in the mudflats of just one region, and the greatest numbers of unique species were recorded from the Central Indo-Pacific, Tropical E Pacific, and Temperate N Pacific (7-9 unique species each; Fig. 5B, Table S1 in the Supplement at www.int-res.com/articles/suppl/ m604p001_supp.pdf).

Globally the Annelida dominated the mudflat assemblages, accounting for around half of all macrofauna. All biogeographic regions contained $>25 \%$ annelids (Fig. 6C), and the Temperate N Atlantic assemblage comprised $20 \%$ more Annelida than in the Tropical Atlantic (Table 4, Fig. 6C). Of the Annelida, the polychaetes dominated (25 to $53 \%$ of the assemblage, Fig. 6D), and the oligochaetes comprised between 5 and $20 \%$ of the assemblages, with higher proportions in the Temperate N Atlantic compared to any other region (Table 4, Fig. 6D).

The Arthropoda comprised $12 \%$ of the assemblage in the Temperate N Atlantic and up to $67 \%$ in the Tropical E Pacific where they were significantly more abundant (Table 4) than in the Temperate N Atlantic, Temperate N Pacific, Temperate Australasia and Central Indo-Pacific regions $(p<0.05)$. Similarly, the Tropical Atlantic mudflats contained significantly more arthropods than the Central Indo-Pacific or any of the temperate regions (Table 4, Fig. 6C). Across all of the 7 regions most of the arthropods were Amphipoda (5 to $26 \%$ ). In Temperate S America the proportions of amphipods were greater than in the Cen- 
Table 3. Pairwise ANOSIM and dissimilarity percentage (SIMPER) of taxonomic composition between 7 biogeographic regions (taxa that cumulatively contributed $\sim 50 \%$ of the dissimilarity between regions are provided in Table S2 in the Supplement and in Fig. 5B). Comparisons are only included for regions that differed significantly (all R-values at $\mathrm{p}<0.01$ )

\begin{tabular}{|lccc|}
\hline Region comparisons & \multicolumn{2}{c}{ ANOSIM statistics } & $\begin{array}{c}\text { SIMPER } \\
\text { dissimilarity (\%) }\end{array}$ \\
& $\mathrm{R}$ & $\mathrm{p}$ & \\
Temperate N Atlantic & & & 99 \\
Temperate S America & 0.717 & $<0.01$ & 96 \\
Temperate Australia & 0.553 & $<0.01$ & 98 \\
Central Indo-Pacific & 0.553 & $<0.01$ & 99 \\
Tropical E Pacific & 0.727 & $<0.01$ & 99 \\
Tropical Atlantic & 0.719 & $<0.01$ & 96 \\
Temperate N Pacific & 0.530 & $<0.01$ & \\
Tropical Atlantic & & & 99 \\
Temperate S America & 0.741 & $<0.01$ & 99 \\
Temperate Australia & 0.789 & $<0.01$ & 98 \\
Temperate N Pacific & 0.510 & $<0.01$ & 99 \\
Central Indo-Pacific & 0.941 & $<0.01$ & \\
Tropical E Pacific & 0.868 & $<0.01$ & 99 \\
Central Indo-Pacific & & & 97 \\
Tropical E Pacific & 0.968 & $<0.01$ & 98 \\
Temperate N Pacific & 0.650 & $<0.01$ & 98 \\
Temperate S America & 0.917 & $<0.01$ & 98 \\
Temperate Australia & 0.894 & $<0.01$ & 97 \\
Temperate S America & & & \\
Temperate N Pacific & 0.215 & $<0.01$ & \\
Temperate Australia & 0.304 & $<0.01$ & \\
& & & \\
\hline
\end{tabular}

ities contributed to $>5 \%(73 \%$ cumulatively) of the dissimilarity between these 2 regions (Fig. 7B). The proportions of taxa with body size $<1 \mathrm{~cm}$, predator avoidance behaviour, tube dwelling, direct larval development, deposit feeding, limited movement and surface modifying bioturbation were significantly higher in the Tropical Atlantic region, whereas exoskeletons were more common in the Central Indo-Pacific (MannWhitney U-test, $\mathrm{p}<0.05$, Fig. 7B).

\section{Latitudinal variations in the composition of mudflat macrofaunal assemblages}

The taxonomic (ANOSIM, R $=0.42$, $\mathrm{p}<$ 0.01; Fig. 4A) and trait composition (ANOSIM R =0.20, p < 0.01; Fig. 4B) of mudflat macrofauna significantly differed between the tropical, subtropical and temperate climatic zones. The polar zone was excluded from the analyses because it was represented by one dataset only. Pairwise ANOSIM showed that all 3 climatic zones significantly differed

tral Indo-Pacific, Tropical Atlantic and Temperate N Atlantic (Fig. 6D), and the latter contained more than the Tropical Atlantic (Fig. 6D, Table 4). The decapods dominated in the Tropical E Pacific $(\sim 30 \%$ of the assemblage) and constituted $<10 \%$ in the other regions (Fig. 6D). Tanaids occurred in only 4 regions (Fig. 6D) and comprised almost one third of the assemblage in the Tropical Atlantic mudflats; significantly more than any other region (Table 4).

The Mollusca comprised 19 to $35 \%$ of assemblages globally (Fig. 6C), and in the Central Indo-Pacific and Temperate North Atlantic the Mollusca comprised significantly greater proportions of the assemblage than in Temperate S America (Table 4). Bivalves occurred in all regions (Fig. 6D) and greater proportions occurred in Temperate Australian mudflats than in Temperate S America (Table 4, Fig. 6D), which contained $<5 \%$. Central Indo-Pacific mudflats contained the greatest proportions of gastropods compared with any of the temperate regions (Table $4, \mathrm{p}<0.05$ ) and were absent from the Temperate S America and Tropical East Pacific regions.

Only the Central Indo-Pacific and the Tropical Atlantic regions significantly differed in trait composition (ANOSIM, R =0.17, $\mathrm{p}<0.01$ ). Nine trait modal- in both taxonomic and trait composition (Fig. 4A, Table 5). Taxa from the tropical mudflats were distinct from those in the subtropical and temperate zones $(<2 \%$ similar), while the subtropical assemblage was $\sim 8 \%$ similar to the temperate (Table 5 ; Fig. 4A). The degree of similarity in trait composition between the 3 zones was 20 to $30 \%$ higher than for taxonomic composition (Table 5). The taxonomic composition within each climatic zone (SIMPER mean similarity 13 to $16 \%$ ) was also more heterogeneous than trait composition (SIMPER mean similarity 30 to $38 \%$ ). Thus, the taxonomic composition was more variable both within and between climatic zones compared with the trait composition.

A total of 34 taxa contributed to $50 \%$ of the cumulative taxonomic dissimilarity between the climatic zones (Fig. 5A), and of these, 6 were present in all 3 zones (the superclass Oligochaeta; the phyla Nemertea; the Capitella capitata and Heteromastus filiformis species complexes [Hutchings \& Rainer 1982; the genera Corophium and Tharyx]. Eleven of the 34 taxa only occurred in the mudflats of the tropical zone, while 6 were restricted to the temperate zone, and none occurred exclusively in the subtropics (Fig. 5A). 


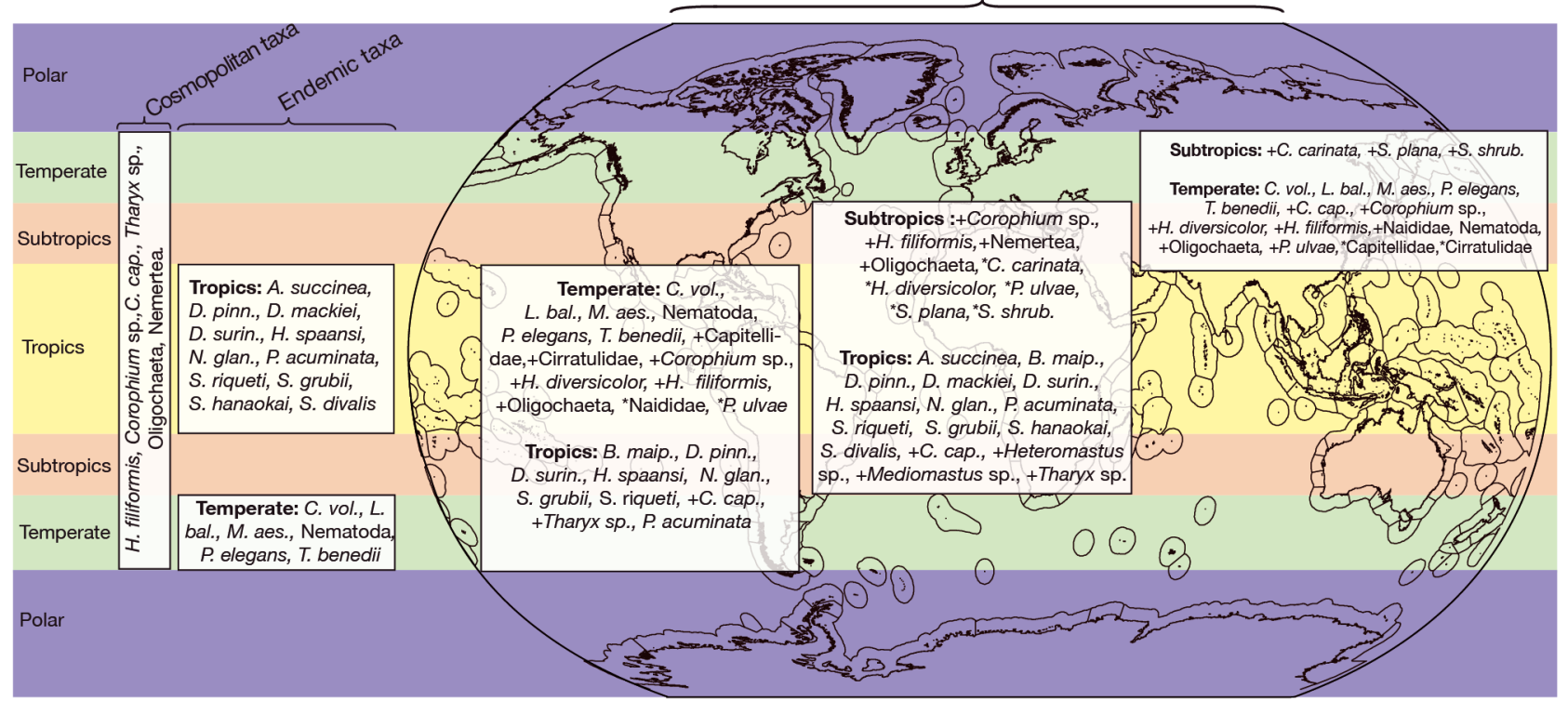

B

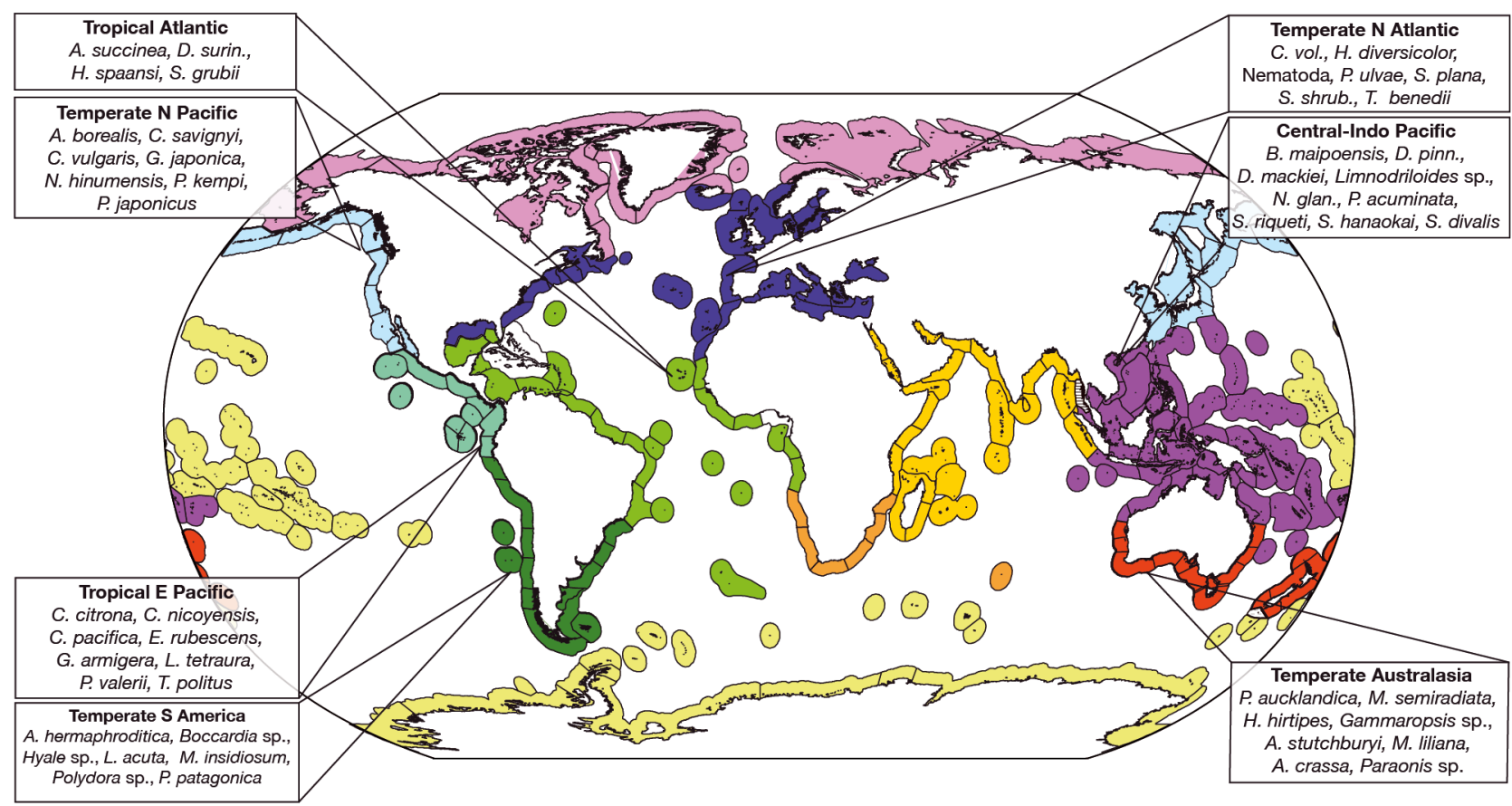

\section{Regions included in the analysis:}

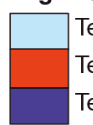

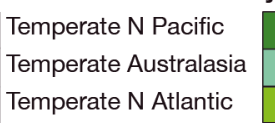

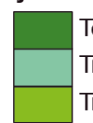

Regions with only one dataset:

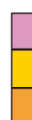

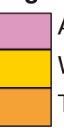

Western Indo-Pacific

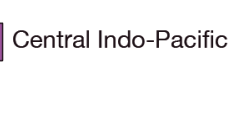

Regions lacking data:

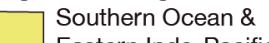

Eastern Indo-Pacific

Fig. 5. Taxonomic differences in mudflat macrofauna between the climatic zones and biogeographic regions. (A) Cosmopolitan taxa and those that were unique to specific zones (left); and taxa that cumulatively contributed to $50 \%$ of the taxonomic dissimilarity between zones (and the direction of the difference; right). Symbols: ' + ' indicates the abundance of taxa is higher compared with the other zone; ${ }^{\prime * \prime}$ indicates taxa found only in 1 zone (of the 2-zone comparison); the absence of any symbol indicates apparently endemic taxa (Table 3, Table S3 in the Supplement). (B) Taxa unique to mudflats in one region (Table S2 in the Supplement); endemic species as determined from the Ocean Biogeographic Information System (OBIS 2018) are shown in Table S1 in the Supplement. Some regions contained little or no data and were excluded from the statistical analyses. The ecoregions (subdivisions of the biogeographic regions of Spalding et al. 2007) that contained taxonomic data have thicker outlines. Biogeographic regions from Spalding et al. (2007). Taxa abbreviations: B. maip. $=$ Borniopsis maipoensis; C cap. $=$ Capitella capitata; . vol. $=$ Corophium volutator D. pinn. $=$ Dendronereis pinnaticirris $;$. surin. $=$ Discapseudes surinamensis L. bal. $=$ Limecola balthica; M. aes. = Manayunkia aestuarina; N. glan. = Neanthes glandicincta; S. shrub. = Streblospio shrubsolii. See Table S1 for full taxa list 

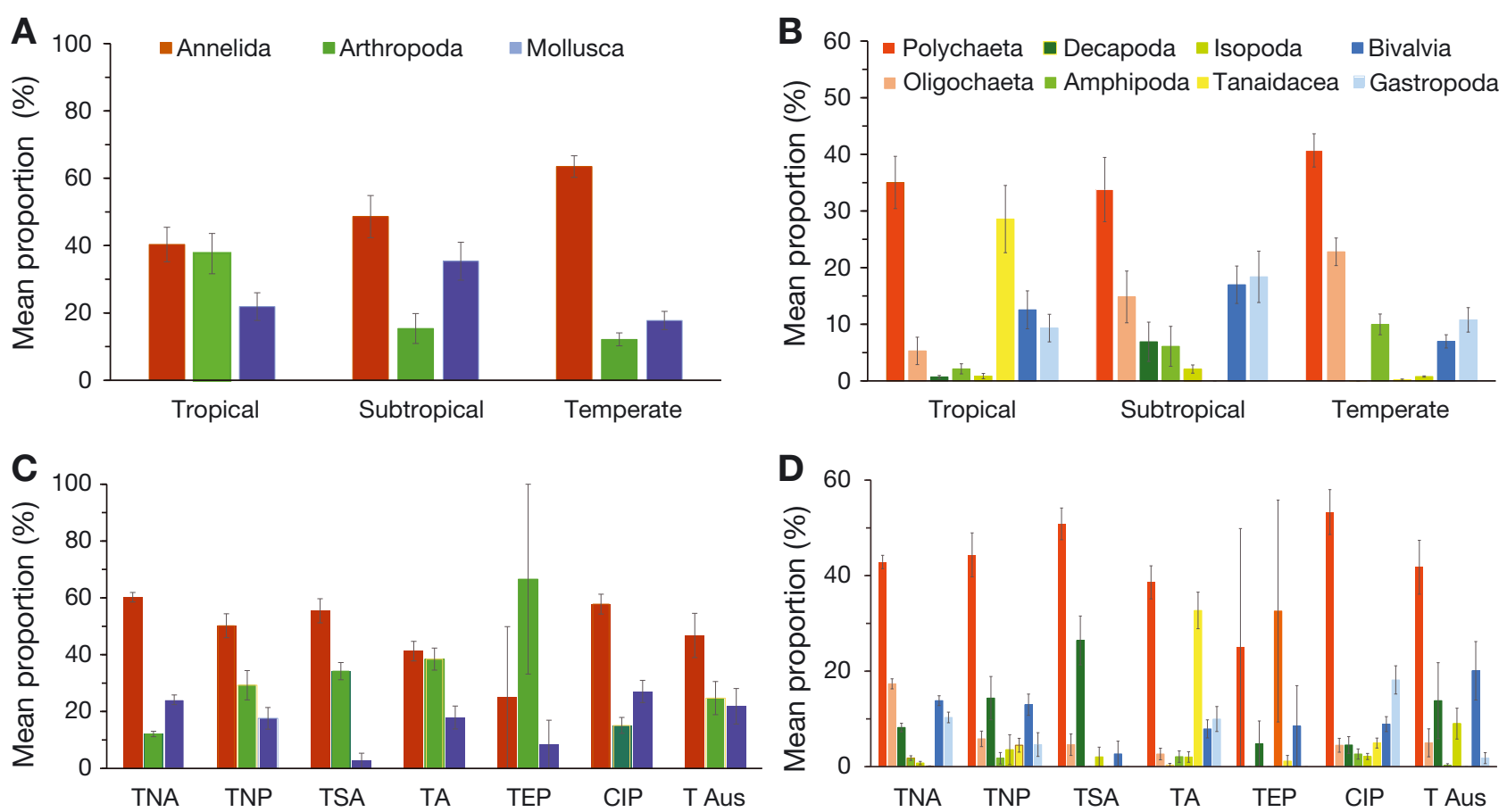

Fig. 6. Proportions of the key phyla, classes and orders in the different climatic zones and biogeographic regions. (A) The proportion (mean $\pm \mathrm{SE}$ ) of phyla, and (B) the main taxonomic classes and orders of the total number of individuals (standardised within each dataset) for the 3 climatic zones. (C) The proportion (mean \pm SE) of phyla, and (D) the main taxonomic classes and orders of the total number of individuals recorded (standardised within each dataset) within the mudflat assemblages of the 7 different biogeographic regions. Abbreviations: TNA = Temperate N Atlantic $;$ TNP $=$ Temperate N Pacific; TSA = Temperate $\mathrm{S}$

America $; \mathrm{TA}=$ Tropical Atlantic $; \mathrm{TEP}=$ Tropical E Pacific $; \mathrm{CIP}=$ Central Indo-Pacific $; \mathrm{T}$ Aus $=$ Temperate Australasia

Table 4. ANOVA and post hoc Tukey test results for comparisons of the proportions (arcsine transformed) of key taxa groups between the 7 biogeographic regions and 3 climatic zones (proportions shown in Fig. 6). Comparisons are only included for regions/zones that significantly differed

\begin{tabular}{|c|c|c|c|c|}
\hline \multirow[t]{2}{*}{ Taxa group } & \multicolumn{3}{|c|}{ ANOVA results } & \multirow[t]{2}{*}{ Post hoc Tukey comparisons } \\
\hline & $F$ & $\mathrm{df}, \mathrm{n}$ & $\mathrm{p}$ & \\
\hline \multicolumn{5}{|c|}{ Biogeographic region comparisons } \\
\hline Annelida & 3.49 & 6,153 & $<0.01$ & Temperate N Atlantic \& Tropical Atlantic $(\mathrm{p}<0.01)$ \\
\hline Oligochaeta & 14.44 & 6,153 & $<0.01$ & Temperate N Atlantic $\&$ all other 6 regions $(\mathrm{p}<0.05)$ \\
\hline \multirow[t]{3}{*}{ Arthropoda } & 22.34 & 6,153 & $<0.01$ & $\begin{array}{l}\text { Temperate N Atlantic \& Temperate S America, Temperate N Pacific, Tropical Atlantic, } \\
\text { Central Indo-Pacific }(\mathrm{p}<0.05)\end{array}$ \\
\hline & & & & $\begin{array}{l}\text { Tropical E Pacific \& Temperate N Atlantic, Temperate N Pacific, Temperate Australia, } \\
\text { Central Indo-Pacific }(\mathrm{p}<0.05)\end{array}$ \\
\hline & & & & Tropical Atlantic \& Central Indo-Pacific $(\mathrm{p}<0.05)$ \\
\hline \multirow[t]{2}{*}{ Amphipoda } & 6.99 & 6,153 & $<0.01$ & $\begin{array}{l}\text { Temperate S America \& Temperate N Atlantic, Tropical Atlantic, Central Indo-Pacific } \\
(\mathrm{p}<0.05)\end{array}$ \\
\hline & & & & Temperate N Atlantic \& Tropical Atlantic $(\mathrm{p}<0.05)$ \\
\hline Decapoda & 12.79 & 6,153 & $<0.01$ & Tropical Atlantic \& all other 6 regions $(p<0.01)$ \\
\hline Tanaidacea & 87.79 & 6,153 & $<0.01$ & $\begin{array}{l}\text { Tropical Atlantic \& Temperate N Pacific, Temperate N Atlantic, Tropical East Pacific, } \\
\text { Central Indo-Pacific }(\mathrm{p}<0.01)\end{array}$ \\
\hline Mollusca & 2.79 & 6,153 & $<0.05$ & $\begin{array}{l}\text { Central Indo Pacific \& Temperate S America }(\mathrm{p}<0.05) \\
\text { Temperate N Atlantic \& Temperate S America }(\mathrm{p}<0.05)\end{array}$ \\
\hline Bivalvia & 3.43 & 6,153 & $<0.01$ & Temperate Australia \& Temperate S America $(\mathrm{p}<0.01)$ \\
\hline Gastropoda & 4.79 & 6,153 & $<0.01$ & $\begin{array}{l}\text { Central Indo-Pacific \& Temperate N Atlantic, Temperate S America, Tropical E } \\
\text { Pacific, Temperate N Pacific, Temperate Australia }(\mathrm{p}<0.05)\end{array}$ \\
\hline \multicolumn{5}{|r|}{ 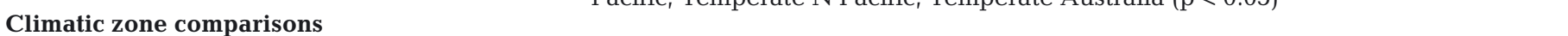 } \\
\hline Annelida & 6.60 & 2,159 & $<0.01$ & Temperate \& Tropical $(\mathrm{p}<0.01)$ \\
\hline Oligochaeta & 8.00 & 2,159 & $<0.01$ & Temperate \& Tropical $(\mathrm{p}<0.01)$ \\
\hline Arthropoda & 15.91 & 2,159 & $<0.01$ & $\begin{array}{l}\text { Tropical \& Temperate }(\mathrm{p}<0.01) \\
\text { Tropical \& Subtropical }(\mathrm{p}<0.01)\end{array}$ \\
\hline Amphipoda & 3.41 & 2,159 & $<0.05$ & Temperate \& Subtropical $(\mathrm{p}<0.05)$ \\
\hline Decapoda & 8.91 & 2,159 & $<0.05$ & Temperate \& Subtropical $(\mathrm{p}<0.01)$ \\
\hline Tanaidacea & 30.50 & 2,159 & $<0.05$ & Temperate \& Tropical $(\mathrm{p}<0.01)$ \\
\hline Isopoda & 7.00 & 2,159 & $<0.05$ & Subtropical \& Temperate $(\mathrm{p}<0.01)$ \\
\hline Mollusca & 3.72 & 2,159 & $<0.01$ & Subtropical \& Temperate $(\mathrm{p}<0.01)$ \\
\hline
\end{tabular}


Fig. 7. Proportion (mean \pm SE) of each trait modality (of the total number of individuals) that cumulatively contributed to (A) $50 \%$ of the dissimilarity between zones (trait modalities that individually contributed $>5 \%$ to the dissimilarity are indicated by ${ }^{\prime * \prime}$ ); and (B) $70 \%$ of the dissimilarity between the Temperate N Atlantic and Tropical Atlantic regions (all traits contributed $>5 \%$ to the SIMPER dissimilarity). Those trait modalities that significantly differed (Mann-Whitney $U$-test) between 2 zones or regions are in bold, and for (A), differences between 3 zones are underlined. Trait modalities: $\mathrm{A} 1=<1 \mathrm{~cm}$ body size $; \mathrm{B} 3=$ vermiform body shape $; \mathrm{C} 2=$ predator avoidance; $\mathrm{C} 3=$ exoskeleton; $\mathrm{E} 2=1$ to $2 \mathrm{yr}$ life span; F1 = direct larval development; F2 = planktotrophic larval development; D2 = burrow dwelling; D3 = tube dwelling; G1 = deposit feeding; I2 = limited movement; J2 = surface modifying bioturbation (see Table 2)

Consistent with the distribution observed for biogeographic regions the proportions of Annelida were $20 \%$ higher in the temperate zone compared to the tropics (Table 4, Fig. 6A). Both the polychaetes and oligochaetes (Fig. 6B) were numerically important with significantly higher proportions of oligochaetes in the temperate zone compared to the tropics (Table 4, Fig. 6B). The higher proportions of arthropods in the tropical regions were also apparent for the tropical zone (Table 4, Fig. 6A) where the proportions of Arthropoda and Annelida were nearly equal ( $40 \%$ each). Similarly, more amphipods occurred in the temperate zone than in the tropics (Table 4), there were more decapods in the subtropics and more tanaids in the tropics (Table 4, Fig. 6B). Additionally, although they did not differ between regions, the isopods were more prevalent in the subtropical zone (Table 4).

Table 5. Pairwise ANOSIM and similarity percentage (SIMPER) comparisons of the taxonomic and trait composition of mudflats in the different climatic zones. Taxa that contributed to the dissimilarity between zones, and the nature of the differences are provided in Table S3 in the Supplement

\begin{tabular}{|c|c|c|c|c|c|c|}
\hline \multirow[t]{3}{*}{ Climatic zones } & \multicolumn{3}{|c|}{ Taxonomic Composition } & \multicolumn{3}{|c|}{ Trait Composition } \\
\hline & \multicolumn{2}{|c|}{ ANOSIM } & \multirow{2}{*}{$\begin{array}{c}\text { SIMPER } \\
\text { mean } \\
\text { dissimilarity } \\
(\%)\end{array}$} & \multicolumn{2}{|c|}{ ANOSIM } & \multirow{2}{*}{$\begin{array}{c}\text { SIMPER } \\
\text { mean } \\
\text { dissimilarity } \\
(\%)\end{array}$} \\
\hline & $\mathrm{R}$ & $\mathrm{p}$ & & $\mathrm{R}$ & $\mathrm{p}$ & \\
\hline Tropical \& Subtropical & 0.23 & $\leq 0.01$ & 98 & 0.19 & $\leq 0.01$ & 29 \\
\hline Tropical \& Temperate & 0.55 & $\leq 0.01$ & 99 & 0.25 & $\leq 0.01$ & 24 \\
\hline Temperate \& Subtropical & 0.27 & $\leq 0.01$ & 92 & 0.36 & $\leq 0.01$ & 19 \\
\hline
\end{tabular}
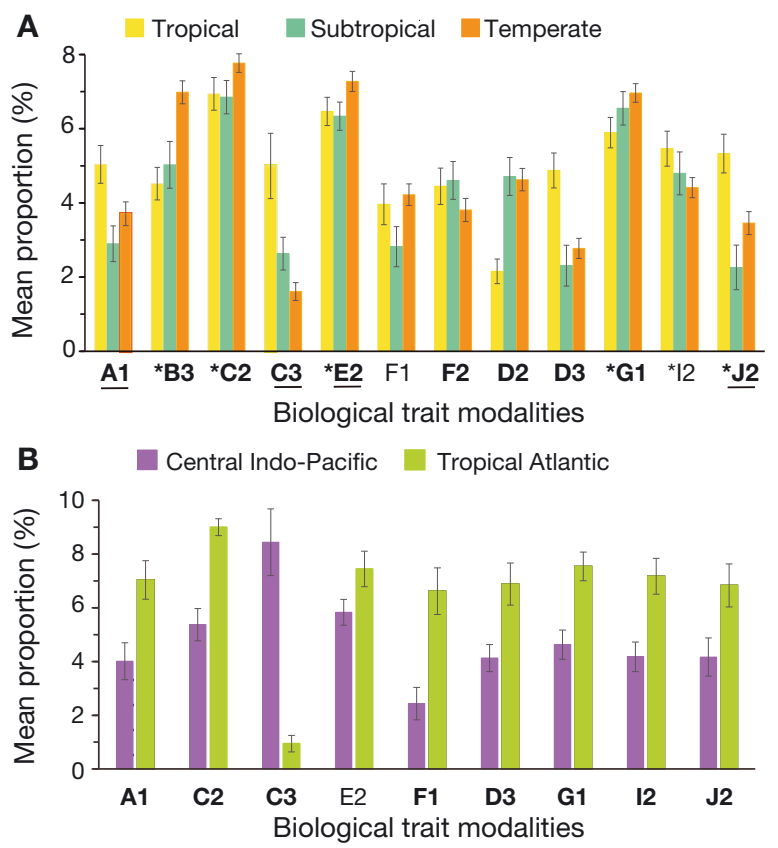

The regional differences in the proportions of Mollusca were generalised as higher proportions in the subtropics compared with the temperate zone (Table 4, Fig. 6A); significantly more bivalves in the subtropics compared with either of the other zones; and the proportions of gastropods did not vary (Table 4, Fig. 6B).

Twelve trait modalities contributed to $50 \%$ of the cumulative dissimilarity between zones, and of these, 10 significantly differed (Kruskal-Wallis test, $\mathrm{p}<0.01$; Fig. 7). Within tropical mudflats, exoskeletons were twice as abundant as in the subtropics, and they were 4 times more common than in temperate mudflats (Fig. 7). Traits for body length $<1 \mathrm{~cm}$ (Mann-Whitney $U$-test, $\mathrm{p}<0.05)$, organisms inhabiting tubes and those with surface-modifying bioturbation were more abundant in the tropics than either of the other 2 zones (Mann-Whitney $U$-test, $\mathrm{p}<0.01$ ); however, taxa with traits for 1 to 2 yr longevity, direct larval development, deposit feeding and predator avoidance were more abundant in the temperate zone (Mann-Whitney $U$-test, p < $0.05)$. Significantly higher proportions of burrow dwellers occurred in both the temperate and subtropical zones (Mann-Whitney $U$-test, p < 0.01). In the temperate zone 
higher proportions of taxa with vermiform body shapes (Fig. 7) presumably reflected the large differences in the proportions of Annelida (Fig. 6A).

\section{DISCUSSION}

This study is based on a unique and comprehensive world-wide dataset of taxonomic and trait composition for mudflat macrofauna. Within intertidal soft-sediments, macrofauna deliver many important ecosystem functions that underpin valuable ecosystem services (Costanza et al. 2014). Despite their value, the present study is the first to investigate global patterns in the biological trait composition and ecological functioning of mudflats. Analysis of 163 datasets showed that biogeographic differences in taxonomic composition resulted in differences in the biological trait composition of the assemblages. However, traits showed substantially less variability between climatic zones and biogeographic regions than taxonomic composition. This suggests that globally the ecosystem functions driven by macrofauna within, and the ecosystem services available from, mudflats are largely conserved. The taxonomic differences do not necessarily manifest as functional differences (Costello et al. 2015, Dencker et al. 2017).

This global synthesis of mudflat data is ultimately limited by the extent and quality of the source data. The 2 scientific databases used (WoS and SCOPUS) are regarded as the most comprehensive in the field, and each had $\sim 20$ to $40 \%$ unique papers (that met our predefined criteria) which is consistent with prior bibliographic analyses (Vieira \& Gomes 2009). The intensity of publication varied between biogeographic regions and climatic zones, with half of all papers coming from the Temperate N Atlantic region. Most work was conducted in developed countries with extensive mudflats e.g. the USA, UK and France. Similar geographic biases have been observed for data on aquatic invertebrate taxonomy (Tancoigne \& Ollivier 2017), biodiversity (Hendriks \& Duarte 2008) and global rates of seafloor bioturbation (Teal et al. 2008).

Attempts to develop global syntheses, such as the Census of Marine Life (Costello et al. 2010), or global environmental health metrics (United Nations 2016) are compromised by data deficiencies. Mudflats in the Polar zones, the Western Indo-Pacific, Eastern Indo-Pacific and Temperate $\mathrm{S}$ African regions were data-poor and constrained the breadth of our analyses. For instance, in the unique environments of Antarctica large numbers of endemic taxa occur, exhibiting gigantism, high longevity and late matu- rity, and particular taxonomic groups are very diverse e.g. isopods, ostracods, nematodes, pycnogonids and sponges (Brandt et al. 2007, Barnes et al. 2009). Thus, these assemblages may also exhibit unique functional attributes that were not elucidated here. Whilst data deficiencies can be addressed by increasing current research efforts, the development of new approaches for standardising data collected previously but with differing methodologies (e.g. Fig. 1) could also help to considerably expand the global mudflat dataset.

\section{The biogeography of global mudflats}

Understanding spatial and temporal variations in taxonomic composition has become a central theme in ecology for describing macroscale patterns of biodiversity (Gaston 2000, Costello et al. 2010, StuartSmith et al. 2013). Such work is often used to identify spatial (Dittmann 2002, Barboza \& Defeo 2015, Defeo et al. 2017) and temporal changes in ecosystem health and functioning (Pereira et al. 2010, Snelgrove 2010, United Nations 2016). The estimates of total species richness showed that, as expected, biodiversity was highest in the tropical mudflats (Fig. 3), but without the latitudinal cline found in previous studies (Attrill et al. 2001, Dittmann 2002, McLachlan \& Dorvlo 2005), perhaps due to differences between the latitudinal zone delimitations by the various authors.

Approximately half of all individuals recorded in the global mudflat macrofaunal species pool were annelids, with polychaetes dominating across all biogeographic regions and climatic zones. Molluscs and arthropods also comprised substantial proportions of the remaining fauna (Fig. 6A). Significantly, however, there were differences in the taxonomic composition of the fauna at lower levels of discrimination such that the relative contributions of oligochaetes, decapods, tanaids, isopods and bivalves significantly differed between regions and climatic zones. The trend for proportionally more decapods and bivalves in the tropics, and the regional restriction of the tanaids, match previous observations (Boschi 2000, Crame 2000, Blazewicz-Paszkowycz et al. 2012). However, the asymmetric global distribution of isopods (Poore \& Bruce 2012) was not apparent for mudflats, suggesting that the 'excess' diversity is in offshore habitats and/or ocean regions in the southern hemisphere where data were lacking (Fig. 5B).

The taxonomic composition of mudflat macrofauna varied between all the climatic zones and many biogeographic regions. Present-day marine biogeogra- 
phy is determined by historic patterns of speciation and biological or physical isolation and/or connection that alter features of the physicochemical environment, and facilitate or inhibit the dispersal and intermixing of species pools (Spalding et al. 2007, Defeo et al. 2017). For instance, the considerable taxonomic dissimilarity (>99\%) between the Tropical Atlantic, Central Indo-Pacific and Tropical Eastern Pacific regions probably reflects the formation of the Isthmus of Panama 20 million years ago, when water exchange between the tropical regions of the 2 oceans ceased. The subsequent lack of faunal exchange, changes in ocean currents (e.g. formation of the Gulf Stream) and increasing salinity in the Atlantic led to the development of distinct faunas (Schneider \& Schmittner 2006, Hemingson \& Bellwood 2018).

\section{Global variations in biological traits and ecosystem functioning}

The greater similarity in traits compared with taxonomic composition between zones and regions suggests that as the identity of taxa changed, the pool of biological and physical features in the assemblage remained broadly the same; it therefore follows that ecological functioning was maintained. This does not necessarily require direct species replacement by functionally similar taxa (Naeem et al. 2002, Norling et al. 2007), as, for example, a filter feeding bivalve that provides biogenic habitat in one region may be represented functionally by, e.g., a filter feeding ophiuroid and a reef building tube worm in another. Despite the apparent biogeographic convergence of trait composition, there remained some significant differences (Table 6).

The prevalence of smaller body sizes in tropical mudflats conformed to the widely reported trends for the body size, growth rate and longevity of many invertebrates (e.g. Timofeev 2001, Munch \& Salinas 2009, Villarino et al. 2018) and vertebrates (Meiri \& Dayan 2003, Munch \& Salinas 2009) to increase towards higher latitudes. These life history trends are attributed to the impacts of temperature on metabolic rate (Munch \& Salinas 2009), and may explain the tendency for longer relative lifespans in temperate zone mudflats. Similarly, the greater prevalence of direct development in higher latitude mudflats corresponds with observations of changing developmental modes (Fernández et al. 2009), increasing egg size (Marshall et al. 2012) and larval development period towards the poles (O'Connor et al. 2007).
The higher proportions of exoskeletons in tropical zone mudflats may be attributable to the lower energetic cost of producing an exoskeleton (Watson et al. 2017), and fits with prior observations of the greater use of physical (Vermeij 1978) and behavioural antipredatory defences (Fawcett 1984) in the tropical zone. The biotic interaction hypothesis predicts that species interactions, i.e. predation, will be strongest at low latitudes (Schemske et al. 2009, Freestone et al. 2011), and this is thought to have driven high rates of speciation over evolutionary timescales (Mittelbach et al. 2007). Burrowing traits were least common in the tropics, while there was a greater propensity for surface modifying bioturbation and tube dwellers (infaunal or epifaunal) in subtropical mudflats, and burrow dwellers in temperate mudflats: trends that do not seem to have been documented previously. A global analysis by Teal et al. (2008) found no latitudinal or longitudinal trends in bioturbation intensity or mixing depth across marine systems; however, that analysis (Teal et al. 2008) focussed on subtidal environments (with only 8 of the 917 datasets being intertidal).

The differences in biological trait composition between zones/regions may manifest in the macrofaunal contribution to a number of functions (Table 6). However, this would not necessarily produce a net difference in potential functioning. For the functions considered in the present study, the spatial differences might include the following:

(1) Sediment turnover, nutrient cycling and OM decomposition. Species that construct burrows can redistribute sediment both horizontally and vertically, facilitating the redistribution of organic matter and oxygen penetration to depth (Mermillod-Blondin 2011). This enhances organic matter decomposition and remineralisation by microbes (Bolam \& Eggleton 2014), and may accelerate the rate of nitrogen transformation (Douglas et al. 2017). A greater proportion of burrowers in the temperate zone suggest that overall these functions there would be enhanced. However, while all burrow dwelling infauna have the potential to stimulate nutrient cycling (Table 6), the contributions of taxa vary and have differential impacts on functioning. For instance, taxa that surfacemodify overturn less sediment and so may contribute less to these functions than taxa that overturn more sediment and/or burrow deeper.

(2) Biogenic habitat creation. In the tropics, the higher proportions of tube dwellers that perform ecosystem engineering roles may change the physical properties of the sediment-e.g. by retaining fine particles and organic matter, the sediment is sta- 
Table 6. Biological trait differences between climatic zones and/or regions and how these traits could manifest as differences in ecological functioning. Symbols: ' + ' indicates the proportions were higher $\left({ }^{\prime}-\right.$ ' lower) in the first zone or region compared with the second zone or region

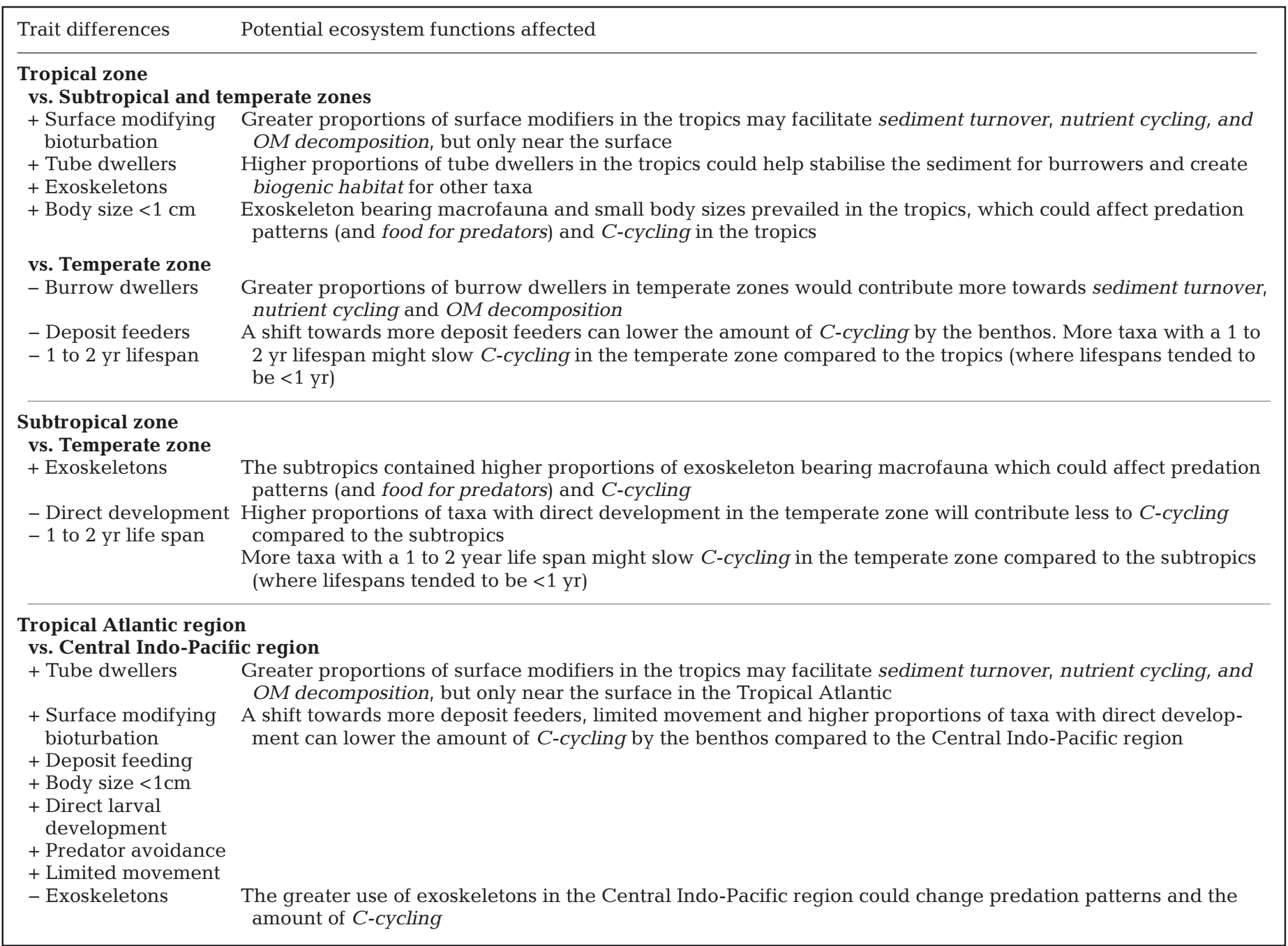

bilised (Eckman et al. 1981) — and increase habitat heterogeneity. These changes affect other members of the assemblage and in turn, ecosystem functioning (Callaway 2006, Rabaut et al. 2007); for instance by creating new biogenic habitat_refugia are available that change species interactions (Bolam \& Fernandes 2003, Rabaut et al. 2007). This new habitat may also facilitate the growth of other biogenic habitats, e.g. mussel reefs (Callaway 2006).

(3) Labile C-cycling. In benthic ecosystems, Ccycling is influenced by many factors; systems predominantly comprised of deposit feeders can process up to $25 \%$ less pelagic carbon than those dominated by suspension feeders. In such systems the coupling of benthic and pelagic productivity is weaker, and less epifaunal and nektonic predators can be supported (Pearson \& Rosenberg 1992). A prevalence of smaller-sized or short-lived taxa would stimulate $\mathrm{C}$-cycling due to the faster turnover rate. Taxa with dispersive reproductive strategies redistribute carbon over wide spatial scales, and between the benthic and pelagic realm, unlike direct developers (Greve et al. 2004), and so the latter contribute less to C-cycling. Thus, in the temperate zone, the potential for C-cycling was less than in the tropical or subtropical zones (Table 6). Furthermore, higher predation rates (e.g. Schemske et al. 2009, Freestone et al. 2011) mean the cycling of labile carbon should be faster in the tropics and subtropics, but anticipating these differences are complicated further by the greater prevalence of prey bearing exoskeletons. 
(4) Food for predators. Mudflat macrofauna are a major source of food for fish, crabs and birds and so support commercial fisheries and large populations of birds. In tropical and subtropical mudflats the greater predation pressure and prevalence of prey defences may, through a co-evolutionary 'arms race', have led to more specialised predators, e.g. shell crushers, compared with the temperate zone (Table 6; Vermeij 1978, Mittelbach et al. 2007). Consequently, the actual supply of food from the benthos to predators might not differ greatly between zones/ regions, although there may be energetic trade-offs.

The biological traits of organisms are, of course, not entirely independent. A small degree of correlation existed between traits; however, this is unlikely to have inflated the degree of similarity between zones/regions. Deficiencies in our knowledge of species biology and behaviour represent an ongoing uncertainty for the attribution of biological traits (Tyler et al. 2012). Larval development, sediment dwelling depth and longevity lacked information for 60 to $70 \%$ of species. Although such limitations can be addressed using data from higher taxonomic designations (e.g. genus or family) or fuzzy coding (Chevene et al. 1994), a degree of uncertainty is retained. Furthermore, the higher proportions of taxa described to species level $(\sim 75 \%)$ in the subtropical and temperate zones will have provided more detail on trait or functional composition and so made comparisons within these regions more conservative than those for tropical regions and zones.

The increasing anthropogenic pressures on the marine environment could soon exceed the resilience thresholds of ecosystems, making them more vulnerable to collapse (Folke et al. 2004). The apparent similarity in biological trait composition $(\sim 30 \%)$ across climatic zones and biogeographic regions, despite taxonomic differences, indicates that mudflat functioning will have some resilience to moderate levels of environmental change via species redundancy. However, it is important to recognise that taxonomically diverse assemblages preserve trait diversity, and thus functioning, that ultimately underpins the delivery of valuable mudflat ecosystem services (Costanza et al. 2014). The data used in this analysis reflected biogeographic variations in species pools that were not subject to significant anthropogenic perturbation. So, whilst the results highlight the extent of redundancy, and thus functional resilience, in natural systems, the management of human pressures to prevent biodiversity loss and habitat degradation in intertidal systems remains a necessity.
Acknowledgements. Facilities were provided by the Environmental Futures Research Institute and School of Environment, Griffith University, the universities of Liverpool and Hull. We would like to extend our thanks to Christopher Hart, Michelle DuBroy and Catherine Pickering for sharing their knowledge of bibliographic approaches, and to Rod Connolly and Matthew Spencer for discussions that helped to develop the work. Constructive feedback from 3 anonymous reviewers and Jana Davis helped to improve the work. The trait data will be made available through SEANOE (www.seanoe.org) after a period of embargo, in the interim please send queries regarding access to the authors.

\section{LITERATURE CITED}

Attrill MJ, Stafford R, Rowden AA (2001) Latitudinal diversity patterns in estuarine tidal flats: indications of a global cline. Ecography 24:318-324

Barboza FR, Defeo O (2015) Global diversity patterns in sandy beach macrofauna: a biogeographic analysis. Sci Rep 5:14515-14523

Barnes DKA, Kaiser S, Griffiths HJ, Linse K (2009) Marine, intertidal, freshwater and terrestrial biodiversity of an isolated polar archipelago. J Biogeogr 36:756-769

Bioinformatics ETI (2018) Marine Species Indentification Portal. KeyToNature programme. www.species-identification.org (accessed 13 April 2018)

* Blazewicz-Paszkowycz M, Bamber R, Anderson G (2012) Diversity of Tanaidacea (Crustacea: Peracarida) in the world's oceans - How far have we come? PLOS ONE 7: e33068

Bolam SG, Eggleton JD (2014) Macrofaunal production and biological traits: spatial relationships along the UK continental shelf. J Sea Res 88:47-58

Bolam SG, Fernandes TF (2003) Dense aggregations of Pygospio elegans (Claparede): effect on macrofaunal community structure and sediments. J Sea Res 49: 171-185

Boschi EE (2000) Biodiversity of marine decapod brachyurans of the Americas. J Crustac Biol 20:337-342

* Brandt A, Gooday AJ, Brandão SN, Brix S and others (2007) First insights into the biodiversity and biogeography of the Southern Ocean deep sea. Nature 447:307-311

* Bremner J, Rogers SI, Frid CLJ (2006) Methods for describing ecological functioning of marine benthic assemblages using biological traits analysis (BTA). Ecol Indic 6: 609-622

Cadotte MW (2011) The new diversity: management gains through insights into the functional diversity of communities. J Appl Ecol 48:1067-1069

Callaway R (2006) Tube worms promote community change. Mar Ecol Prog Ser 308:49-60

Cardinale BJ, Duffy JE, Gonzalez A, Hooper DU and others (2012) Biodiversity loss and its impact on humanity. Nature 486:59-67

Caswell BA, Frid CLJ (2017) Marine ecosystem resilience during extreme deoxygenation: the Early Jurassic oceanic anoxic event. Oecologia 183:275-290

* Caswell BA, Paine M, Frid CLJ (2018) Seafloor ecological functioning over two decades of organic enrichment. Mar Poll Bull 136:212-229

Chevene F, Doléadec S, Chessel D (1994) A fuzzy coding approach for the analysis of long-term ecological data. Freshw Biol 31:295-309 
Costanza R, de Groot R, Sutton P, van der Ploeg S and others (2014) Changes in the global value of ecosystem services. Glob Environ Change 26:152-158

* Costello MJ, Coll M, Danovaro R, Halpin P, Ojaveer H, Miloslavich P (2010) A census of marine biodiversity knowledge, resources, and future challenges. PLOS ONE 5:e12110

* Costello MJ, Claus S, Dekeyzer S, Vandepitte L, Tuama ÉÓ, Lear D, Tyler-Walters H (2015) Biological and ecological traits of marine species. PeerJ 3:e1201

Crame AJ (2000) Evolution of taxonomic diversity gradients in the marine realm: evidence from the composition of recent bivalve faunas. Paleobiology 26:188-214

Dayton PK (1971) Competition, disturbance, and community organization: the provision and subsequent utilization of space in a rocky intertidal community. Ecol Monogr 41: 351-389

Defeo O, Barboza CAM, Barboza FR, Aeberhard WH and others (2017) Aggregate patterns of macrofaunal diversity: An interocean comparison. Glob Ecol Biogeogr 26: 823-834

* Dencker TS, Pecuchet L, Beukhof E, Richardson K, Payne MR, Lindegren M (2017) Temporal and spatial differences between taxonomic and trait biodiversity in a large marine ecosystem: causes and consequences. PLOS ONE 12:e0189731

* Dittmann S (2002) Benthic fauna in tropical tidal flatsa comparative perspective. Wetlands Ecol Manage 10: 189-195

Douglas EJ, Pilditch CA, Kraan C, Schipper LA, Lohrer AM, Thrush SF (2017) Macrofaunal Functional Diversity Provides Resilience to Nutrient Enrichment in Coastal Sediments. Ecosystems 20:1324-1336

Doufy JE, Macdonald KS, Rhode JM, Parker JD (2001) Grazer diversity, functional redundancy, and productivity in seagrass beds: an experimental test. Ecology 82: 2417-2434

Dyer KR (1979) Estuarine hydrography and sedimentation. Estuarine and Brackish Water Sciences Association. Cambridge University Press, Cambridge

Eckman JE, Nowell ARM, Jumars PA (1981) Sediment destabilization by animal tubes. J Mar Res 39:361-373

Fauchald K, Jumars PA (1979) The diet of worms: a study of polychaete feeding guilds. Oceanogr Mar Biol Annu Rev 17:193-284

Faulwetter MS, Markantonatou MV, Pavloudi MC, Papageorgiou N and others (2014) Polytraits: a database on biological traits of marine polychaetes. http:// polytraits.lifewatchgreece.eu (accessed 3 February 2018)

Fawcett MH (1984) Local and latitudinal variation in predation on an herbivorous marine snail. Ecology 65: 1214-1230

Fernández M, Astorga A, Navarrete SA, Valdovinos C, Marquet PA (2009) Deconstructing latitudinal species richness patterns in the ocean: Does larval development hold the clue? Ecol Lett 12:601-611

Fetzer I, Johst K, Schäwe R, Banitz T, Harms H, Chatzinotas A (2015) The extent of functional redundancy changes as species' roles shift in different environments. Proc Natl Acad Sci USA 112:14888-14893

Fitch JE, Crowe TP (2011) Combined effects of temperature, inorganic nutrients and organic matter on ecosystem processes in intertidal sediments. J Exp Mar Biol Ecol 400:257-263

Folke C, Carpenter S, Walker B, Scheffer M, Elmqvist T,
Gunderson L, Holling CS (2004) Regime shifts, resilience, and biodiversity in ecosystem management. Annu Rev Ecol Evol Syst 35:557-581

Freestone AL, Osman RW, Ruiz GM, Torchin ME (2011) Stronger predation in the tropics shapes species richness patterns in marine communities. Ecology 92:983-993

*Frid CLJ, Caswell BA (2016) Does ecological redundancy maintain functioning of marine benthos on centennial to millennial time scales? Mar Ecol 37:392-410

Frid CLJ, Paramor OAL, Brockington S, Bremner J (2008) Incorporating ecological functioning into the designation and management of marine protected areas. Hydrobiologia 606:69-79

Gaston KJ (2000) Global patterns in biodiversity. Nature 405:220-227

Kollasch S, Riemann-Zürneck K (1996) Transoceanic dispersal of benthic macrofauna: Haliplanella luciae (Verrill, 1898) (Anthozoa, Actiniaria) found on a ship's hull in a shipyard dock in Hamburg harbour, Germany. Helgol Meeresunters 50:253-258

Gray JS, Elliott M (2009) Ecology of marine sediments: from science to management. Oxford University Press, Oxford

Greve W, Reiners F, Nast J, Hoffmann S (2004) Helgoland Roads meso- and macrozooplankton time-series 1974 to 2004: lessons from 30 years of single spot, high frequency sampling at the only off-shore island of the North Sea. Helgol Mar Res 58:274-288

*Hemingson CR, Bellwood DR (2018) Biogeographic patterns in major marine realms: function not taxonomy unites fish assemblages in reef, seagrass and mangrove systems. Ecography 41:174-182

* Hendriks IE, Duarte CM (2008) Allocation of effort and imbalances in biodiversity research. J Exp Mar Biol Ecol 360:15-20

*Hillebrand H (2004) Strength, slope and variability of marine latitudinal gradients. Mar Ecol Prog Ser 273:251-267

*Hooper DU, Chapin FS III, Ewel JJ, Hector A and others (2005) Effects of biodiversity on ecosystem functioning: a consensus of current knowledge. Ecol Monogr 75:3-35

*Hutchings P, Rainer S (1982) Designation of a neotype of Capitella filiformis Claparède, 1864, type species of the genus Heteromastus (Polychaeta: Capitellidae). Rec Aust Mus 34:373-380

IPBES (Intergovernmental Science-Policy Platform on Biodiversity and Ecosystem Services) (2016) The methodological assessment report on scenarios and models of biodiversity and ecosystem services. Secretariat of the Intergovernmental Science-Policy Platform on Biodiversity and Ecosystem Services, Bonn

IPCC (Intergovernmental Panel on Climate Change) (2013) Climate change 2013 - the physical science basis. Working Group I Contribution to the Fifth Assessment Report of the Intergovernmental Panel on Climate Change. IPCC, New York, NY

* Kicklighter C, Hay ME (2006) Integrating prey defensive traits: contrasts of marine worms from temperate and tropical habitats. Ecol Monogr 76:195-215

Kristensen E, Penha-Lopes G, Delefosse M, Valdemarsen T, Quintana CO, Banta GT (2012) What is bioturbation? The need for a precise definition for fauna in aquatic sciences. Mar Ecol Prog Ser 446:285-302

Lubchenco J, Gaines SD (1981) A unified approach to marine plant-herbivore interactions. I. Populations and communities. Annu Rev Ecol Syst 12:405-437

MarLIN (Marine Life Information Network) (2006) BIOTIC- 
Biological Traits Information Catalogue. Marine Biological Association of the United Kingdom, Plymouth. www.marlin.ac.uk (accessed 2 February 2018)

Marshall DJ, Krug PJ, Kupriyanova EK, Byrne M, Emlet RB (2012) The biogeography of marine invertebrate life histories. Annu Rev Ecol Evol Syst 43:97-114

McLachlan A, Dorvlo A (2005) Global patterns in sandy beach macrobenthic communities. J Coast Res 21:674-687

MEA (Millennium Ecosystem Assessment) (2005) Ecosystems and human well-being: Synthesis, Millennium Ecosystem Assessment. United Nations, New York, NY

Meiri S, Dayan T (2003) On the validity of Bergmann's rule. J Biogeogr 30:331-351

Mermillod-Blondin F (2011) The functional significance of bioturbation and biodeposition on biogeochemical processes at the water-sediment interface in freshwater and marine ecosystems. J N Am Benthol Soc 30:770-778

Mittelbach GG, Schemske DW, Cornell HV, Allen AP and others (2007) Evolution and the latitudinal diversity gradient: speciation, extinction and biogeography. Ecol Lett 10:315-331

* Munch SB, Salinas S (2009) Latitudinal variation in lifespan within species is explained by the metabolic theory of ecology. Proc Natl Acad Sci USA 106:13860-13864

Murray NJ (2018) Satellite remote sensing for the conservation of East Asia's coastal wetlands. In: Leidner AK, Buchanan GM (eds) Satellite remote sensing for conservation action: case studies from aquatic and terrestrial ecosystems. Cambridge University Press, Cambridge, p 54-81

Naeem S, Loreau M, Inchausti P (2002) Biodiversity and ecosystem functioning: the emergence of a synthetic ecological framework. In: Loreau M, Naeem S, Inchausti P (eds) Biodiversity and ecosystem functioning: synthesis and perspectives. Oxford University Press, Oxford, p 3-11

Norling K, Rosenberg R, Hulth S, Grémare A, Bonsdorff E (2007) Importance of functional biodiversity and speciesspecific traits of benthic fauna for ecosystem functions in marine sediment. Mar Ecol Prog Ser 332:11-23

*'Connor MI, Bruno JF, Gaines SD, Halpern BS, Lester SE, Kinlan BP, Weiss JM (2007) Temperature control of larval dispersal and the implications for marine ecology, evolution, and conservation. Proc Natl Acad Sci USA 104: 1266-1271

OBIS (Ocean Biogeographic Information System) (2018) Ocean Biogeographic Information System. International Oceanographic Data and Information Programme. Intergovernmental Oceanographic Commission of UNESCO. www.iobis.org (accessed 13 April 2018)

Paine RT (1966) Food web complexity and species diversity. Am Nat 100:65-75

* Pearson T, Rosenberg R (1992) Energy flow through the SE Kattegat: a comparative examination of the eutrophication of a coastal marine ecosystem. Neth J Sea Res 28: 317-334

* Pereira HM, Leadley PW, Proença V, Alkemade R and others (2010) Scenarios for global biodiversity in the 21st century. Science 330:1496-1501

Poore GCB, Bruce NL (2012) Global diversity of marine isopods (except Asellota and crustacean symbionts). PLOS ONE 7:e43529

* Queirós AM, Birchenough SNR, Bremner J, Godbold JA and others (2013) A bioturbation classification of European marine infaunal invertebrates. Ecol Evol 3:3958-3985

* Rabaut M, Guilini K, Van Hoey G, Vincx M, Degraer S
(2007) A bio-engineered soft-bottom environment: the impact of Lanice conchilega on the benthic species-specific densities and community structure. Estuar Coast Shelf Sci 75:525-536

Ratnasingham S, Hebert PDN (2007) BOLD: the Barcode of Life Data System (www. barcodinglife.org). Mol Ecol Notes 7:355-364

Rees HL (1984) A note on mesh selection and sampling efficiency in benthic studies. Mar Pollut Bull 15:225-229

Reish DJ (1959) A discussion of the importance of screen size in washing quantitative marine bottom samples. Ecology 40:307-309

Rex MA, Crame JA, Stuart CT, Clarke A (2005) Large scale biogeographic patterns in marine mollusks: A confluence of history and productivity? Ecology 86:2288-2297

Schemske DW, Mittelbach GG, Cornell HV, Sobel JM, Roy $\mathrm{K}$ (2009) Is there a latitudinal gradient in the importance of biotic interactions? Annu Rev Ecol Evol Syst 40: 245-269

Schneider B, Schmittner A (2006) Simulating the impact of the Panamanian seaway closure on ocean circulation, marine productivity and nutrient cycling. Earth Planet Sci Lett 246:367-380

Snelgrove PV (1997) The importance of marine sediment biodiversity in ecosystem processes. Ambio 26:578-583

Snelgrove PV (2010) Part II. The unknown: What has the census learned. In: Discoveries of the census of marine life: making ocean life count. Cambridge University Press, Cambridge, p 69-230

* Sousa WP (1984) The role of disturbance in natural communities. Annu Rev Ecol Syst 15:353-391

* Spalding MD, Fox HE, Allen GR, Davidson N and others (2007) Marine ecoregions of the world: a bioregionalization of coastal and shelf areas. Bioscience 57:573-583

* Stuart-Smith RD, Bates AE, Lefcheck JS, Duffy JE and others (2013) Integrating abundance and functional traits reveals new global hotspots of fish diversity. Nature 501: 539-542

Tancoigne E, Ollivier G (2017) Evaluating the progress and needs of taxonomy since the Convention on Biological Diversity: going beyond the rate of species description. Aust Syst Bot 30:326-336

พ Teal LR, Bulling MT, Parker ER, Solan M (2008) Global patterns of bioturbation intensity and mixed depth of marine soft sediments. Aquat Biol 2:207-218

*Tilman D, Knops J, Wedin D, Reich P, Ritchie M, Siemann E (1997) The influence of functional diversity and composition on ecosystem processes. Science 277:1300-1302

Timofeev SF (2001) Bergmann's principle and deep-water gigantism in marine crustaceans. Biol Bull Russ Acad Sci 28:646-650

Törnroos A, Bonsdorff E, Bremner J, Blomqvist M, Josefson AB, Garcia C, Warzocha J (2015) Marine benthic ecological functioning over decreasing taxonomic richness. J Sea Res 98:49-56

Tyler EHM, Somerfield PJ, Berghe EV, Bremner J and others (2012) Extensive gaps and biases in our knowledge of a well-known fauna: implications for integrating biological traits into macroecology. Glob Ecol Biogeogr 21: 922-934

*Ugland KI, Gray JS, Ellingsen KE (2003) The speciesaccumulation curve and estimation of species richness. J Anim Ecol 72:888-897

United Nations (1992) Convention on Biological Diversity. United Nations, New York, NY 
United Nations (2016) Summary of the First Global Integrated Marine Assessment (First World Ocean Assessment). United Nations, New York, NY

*van der Linden P, Patrício J, Marchini A, Cid N, Neto JM, Marques JC (2012) A biological trait approach to assess the functional composition of subtidal benthic communities in an estuarine ecosystem. Ecol Indic 20:121-133

van der Wegen M, Jaffe B, Foxgrover A, Roelvink D (2017) Mudflat morphodynamics and the impact of sea level rise in South San Francisco Bay. Estuaries Coasts 40:37-49

Vermeij GJ (1978) Biogeography and adaptation: patterns of marine life, Vol 55. Harvard University Press, Cambridge, MA

Editorial responsibility: Jana Davis, Annapolis, Maryland, USA
Vieira ES, Gomes JANF (2009) A comparison of Scopus and Web of Science for a typical university. Scientometrics 81:587-600

Villarino E, Watson JR, Jönsson B, Gasol JM and others (2018) Large-scale ocean connectivity and planktonic body size. Nat Commun 9:142-154

* Walker BH (1992) Biodiversity and ecological redundancy. Conserv Biol 6:18-23

* Watson SA, Morley SA, Peck LS (2017) Latitudinal trends in shell production cost from the tropics to the poles. Sci Adv 3:e1701362

*WoRMS Editorial Board (2016) World Register of Marine Species. Available from www.marinespecies.org at VLIZ

Submitted: May 13, 2018; Accepted: August 20, 2018

Proofs received from author(s): September 20, 2018 